\title{
Modular Approach to the Functionalization of Polymersomes
}

\author{
Sjoerd J. Rijpkema, Sabine G. H. A. Langens, Marnix R. van der Kolk, Katerina Gavriel, B. Jelle Toebes, \\ and Daniela A. Wilson*
}

Cite This: Biomacromolecules 2020, 21, 1853-1864

Read Online

ACCESS

Џlll Metrics \& More

Article Recommendations

Supporting Information

ABSTRACT: Functionalizing polymersomes remains a challenge due to the limitation in reaction conditions applicable to the chemistry on the surface, hindering their application for selective targeting. In order to overcome this limitation, functionalization can be introduced right before the self-assembly. Here, we have synthesized a library (32 examples) of PEG- $b$-PS and PEG- $b$ PDLLA with various functional groups derived from the aminefunctionalized polymers, leading to functionally active polymersomes. We show that polymersome formation is possible via the general method with all functionalized groups and that these handles are present on the surface and are able to undergo reactions. Additionally, this methodology provides a general synthetic tool to tailor the functional group of the polymersome right before self-assembly, without limitation on the reaction conditions.

\section{INTRODUCTION}

In natural systems, amphipathic polymers are abundant building blocks that self-assemble to form ordered systems, such as vesicles and cell membranes. To emulate this behavior, polymeric systems that are biocompatible and lack toxicity have been developed and used for the construction of biomimetic materials that can be used for medical applications. ${ }^{1-4}$ Polymersomes can be made using a wide variety of polymers ${ }^{5,6}$ and have been used extensively as vesicles for drug delivery, ${ }^{7-10}$ as nanoreactors, ${ }^{11,12}$ and for motion. ${ }^{13}$ In order to attain these functionalities, polymersomes require incorporation of specific materials or chemical groups. In the case of drug delivery and motion, this is often done by encapsulation. ${ }^{14}$ However, encapsulation alone is quite limited in terms of chemical reactions and stability. Robust and efficient conjugation methods are essential to broadening the scope and accessibility of polymersomes in the medical field. ${ }^{15,16}$ Common methods of conjugation used in the nanoparticle and polymersome field include click chemistry, ${ }^{17-19}$ inverse-electron demand Diels-Alder, ${ }^{20-22}$ oxime chemistry, ${ }^{23-25}$ thiol-ene chemistry, ${ }^{26-28}$ and DielsAlder, ${ }^{29-31}$ among others. However, this large toolbox of ligation techniques is not always easily accessible due to the limitations in functionalization of nanomaterials.

Many nanomaterials are made before the desired functional groups are introduced. After the self-assembly has taken place, new functional groups can be attached. Postmodification can however be very restrictive, due to low stability of membranes in various conditions or accessibility of the reactants. ${ }^{32}$ Examples of postmodification are prevalent in literature, but are mostly made on a case-to-case basis. The group of Meier, for instance, has worked on functionalizing the surface of polymersomes to make them biocompatible, using hydrazones. ${ }^{33}$ Similarly, azides have also been used to functionalize the surface, ${ }^{34}$ and the group of Santos has looked into coating the surface with a long peptide chain for targeting. ${ }^{35}$ Prefunctionalization of these materials would enable a faster and simpler formation of nanomaterials and also allow for dualtargeting upon postfunctionalization. ${ }^{36}$ Although examples of this also exist within the literature, they are commonly made from scratch to be used for a single goal. ${ }^{36,37}$ In all of these examples, a unifying strategy for prefunctionalization is lacking. A limitation is the need for the handles to be compatible with the synthetic preparation of the building block, as well as with the self-assembly process, as incompatibility may lead to loss of that functionality or morphology due to the lack of control in positioning of the handle. ${ }^{38,39}$ In the case of poly(ethylene glycol)- $b$-polystyrene (PEG- $b$-PS), prefunctionalization of the polymer with different functional groups has proven to be successful, giving a window for further investigation into a prefunctional approach with various chemical handles. ${ }^{40}$ For this reason, we decided to use the PEG- $b$-PS as well as the biodegradable poly(ethylene glycol)-b-poly(lactic acid) (PEG-

Special Issue: Anselme Payen Award Special Issue

Received: December 15, 2019

Revised: February 6, 2020

Published: February 7, 2020 
A)

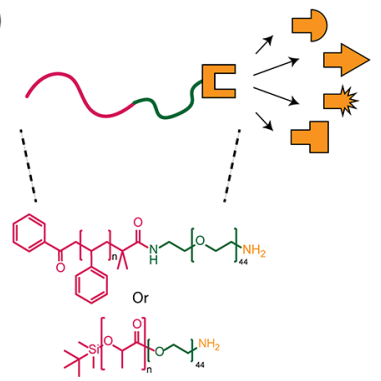

B)

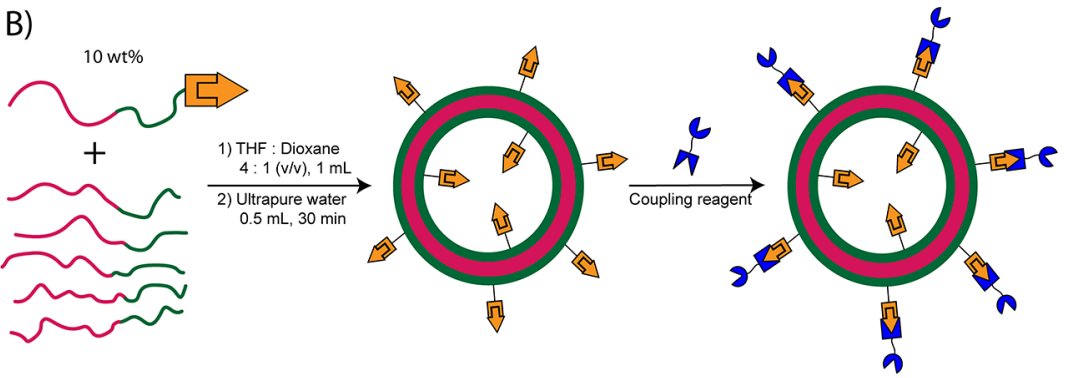

Figure 1. (A) Design of the modular PEG- $b$-PS and PEG- $b$-PDLLA polymers. The amine moiety functions as a base for attaching various functionalities. (B) Polymersomes are made via self-assembly upon slow addition of water $\left(0.5 \mathrm{~mL}, 1 \mathrm{~mL} \mathrm{~h}{ }^{-1}\right) .10 \%$ addition of the functionalized polymers during self-assembly provides functional handles, which can react for further decoration of the polymersome.

b-PDLLA) polymersome-based nanomotors reported by our group $^{13,41}$ as the basis for a library synthesis.

Designing a polymersome with the functionalization incorporated in the polymer before self-assembly could be achieved by direct polymerization of reactive handles to monomers. This is undesirable though, as this would increase the synthetic load immensely, because a new polymer has to be synthesized from scratch for every different ligation desired. Utilizing this approach also requires every synthetic step to tolerate the functional group of the polymer. Therefore, we have designed a method which combines the versatility of prefunctionalization with the high compatibility of postfunctionalization. By first synthesizing a polymer with a functional handle that can, subsequently, form a stable bond with compounds that present the desired functional group, we make a polymer that can function as the base molecule for all other moieties that we want to attach. The reactivity on the polymer is hard to monitor via conventional methods such as NMR, IR and UV, due to the relatively small concentration of the handle compared to the size of the polymer. In order to overcome these problems, we have selected an amine functionality. The use of amine-functionalized polymers is already prevalent in the polymersome field, though mainly used for postmodifications. One example of premodification is shown by Zou et al., who have used amine-capped polymers to introduce new functionalities. ${ }^{42} \mathrm{We}$ aim to use their versatility for a simple to use prefunctionalization method. Amines can form incredibly stable amide bonds, for which reaction conditions have been researched immensely, ${ }^{43-45}$ and completion of the reaction can be followed with $99.9 \%$ accuracy via the Kaiser test. ${ }^{46,47}$ Amine-functionalized PEG- $b$ PS and PEG- $b$-PDLLA can bind various small molecules via an amide bond, which contains a different functionalization on the other end (Figure 1A). We aim to show the diversity possible via this modular approach by providing examples not only of moieties useful for chemical ligation, but also biotargeting and monitoring of the polymersome. When self-assembling the polymersome from the desired polymer, we then incorporate $10 \%$ of the functional polymer into the polymersomes (Figure 1B). To prove that the handles are available on the surface, we react $\mathrm{DBCO}$-functionalized polymersomes with a 3-azidocoumarin derivative. This compound will become strongly fluorescent upon cycloaddition, allowing for the monitoring of its conjugation onto the polymersome, simply by measuring the fluorescence intensity. ${ }^{48}$

\section{EXPERIMENTAL SECTION}

Materials. All PEG polymers were obtained from AV Chemistry. All other reagents were obtained from commercial sources and were used without purification unless otherwise stated. Solvents were dried by passing over activated alumina columns in a MBraun MB SPS800 under a nitrogen atmosphere and stored under argon. Reactions were carried without the need for an inert atmosphere unless stated otherwise, in which case the reaction was performed under a dry atmosphere of argon. Standard syringe techniques were applied for the transfer of dry solvents and air- or moisture sensitive reagents. Styrene was passed over alumina to remove the inhibitor 4-tertbutylcatechol. Ultrapure Milli-Q water was obtained from QPOD Milli-Q system.

Instrumentation. Nuclear Magnetic resonance (NMR) characterization was carried out on a Bruker AVANCE HD nanobay console with a $9.4 \mathrm{~T}$ Ascend magnet $(400 \mathrm{MHz})$ and a Bruker AVANCE III console with a $11.7 \mathrm{~T}$ UltraShield Plus magnet $(500 \mathrm{MHz})$ equipped with a Bruker Prodigy cryoprobe, in chloroform $\left(\mathrm{CDCl}_{3}\right)$, DMSO- $d_{6}$, or THF- $d_{8}$. NMR spectra were recorded at $298 \mathrm{~K}$ unless otherwise specified. Chemical shifts are given in parts per million (ppm) with respect to tetramethylsilane (TMS, $\delta 0.00 \mathrm{ppm}$ ) as internal standard for ${ }^{1} \mathrm{H}$ NMR. Coupling constants are reported as $J$ values in Hz. Peak assignment is based on $2 \mathrm{D}$ gDQCOSY, ${ }^{1} \mathrm{H}-{ }^{13} \mathrm{C}$ gHSQCED, and ${ }^{1} \mathrm{H}-{ }^{13} \mathrm{C}$ gHMBC spectra. Side group and end of chain signals separated from the bulk polymer ${ }^{1} \mathrm{H}$ signal are only reported when observed with clear $\mathrm{s} / \mathrm{n}$ ratio and no overlap with polymer peaks, and may be (in)visible on other NMR spectrometers or with different concentrations. Gel permeation chromatography (GPC) equipped with PL gel $5 \mu \mathrm{m}$ mixed D column calibrated for polystyrene (580$377400 \mathrm{~g} / \mathrm{mol}$ ) was carried out on a Shimadzu instrument with THF as eluent using differential refractive index and UV $(254 \mathrm{~nm})$ detectors. Transmission electron microscopy (TEM) was carried out on JEOL TEM 1400 equipped with a CCD camera at $60 \mathrm{kV}$. Samples were prepared by dropcasting $5 \mu \mathrm{L}$ of appropriately diluted samples on a carbon-coated $\mathrm{Cu}$ grid (200 mesh) and dried overnight at room temperature. Cryogenic TEM was also carried out with JEOL TEM 2100. Malvern Zetasizer nano $S$ was used for dynamic light scattering (DLS) measurements equipped with $\mathrm{He}-\mathrm{Ne}$ laser of wavelength 633 nm. Fluorescence was measured on a Tecan Spark 200.

Synthesis of Polymers. $\alpha$-tert-Butyloxycarbonyl-polystyrene (1). $\alpha$-tert-Butyloxycarbonyl-polystyrene (1) was prepared as described by Tu et al. ${ }^{49} \mathrm{CuBr}(225 \mathrm{mg}, 1.6 \mathrm{mmol}, 2.3$ equiv) was charged in a flame-dried Schlenk flask. PMDETA $(330 \mu \mathrm{L}, 1.6 \mathrm{mmol}$, 2.3 equiv) in anisole $(5 \mathrm{~mL})$ was added to the flask, after which it was vigorously stirred for $15 \mathrm{~min}$. Styrene $(28.7 \mathrm{~mL}, 250 \mathrm{mmol}, 345$ equiv) was added, and the mixture was degassed for $15 \mathrm{~min}$. The mixture was cooled to $0{ }^{\circ} \mathrm{C}$ and tert-butyl- $\alpha$-bromoisobutyrate (135 $\mu \mathrm{L}, 0.7 \mathrm{mmol}, 1$ equiv) was added, after which the mixture was degassed for another $15 \mathrm{~min}$. The mixture was heated to $90{ }^{\circ} \mathrm{C}$, and the progress of polymerization was followed by ${ }^{1} \mathrm{H}$ NMR. When the desired molecular length was obtained, 1-phenyl-1-trimethylsiloxyethene ( $9.55 \mathrm{~mL}, 46.4 \mathrm{mmol}, 65.5$ equiv) was added to terminate the reaction and left to stir for $2 \mathrm{~h}$. Subsequently the reaction mixture was 
diluted with DCM, extracted with $50 \mathrm{mM}$ EDTA solution twice and once with brine. The washed organic fraction was dried over $\mathrm{MgSO}_{4}$ and concentrated by rotary evaporation. The concentrate was precipitated in ice cold $\mathrm{MeOH}$ and subsequently washed with cold $\mathrm{MeOH}(3 \times)$ and dried in vacuo to obtain 1 as a white solid (10.1 g, 64\%). ${ }^{1} \mathrm{H}$ NMR $\left(500 \mathrm{MHz}, \mathrm{CDCl}_{3}\right) \delta 7.98-7.95$ (m, 2H, PS cap ortho), 7.59-7.54 (m, 1H, PS cap para), 7.49-7.45 (m, 2H, PS cap meta), 7.24-6.86 (m, PS arom. ortho and para), 6.58-6.28 (m, PS arom. meta), $2.30-1.70$ (m, PS backbone $\mathrm{CH}$ ), 1.70-1.17 (m, PS backbone $\left.\mathrm{CH}_{2}\right), 1.30-1.21\left(\mathrm{~m}, 9 \mathrm{H},{ }^{t} \mathrm{Bu}\right), 0.87-0.78(\mathrm{~m}, 6 \mathrm{H}, b) .{ }^{13} \mathrm{C}$ NMR $\left(125 \mathrm{MHz}, \mathrm{CDCl}_{3}\right) \delta 198.3,145.0,137.1,133.4,128.6,128.0$, 127.7, 125.5, 79.4, 45.3, 44.2, 40.7, 29.0, 21.1. $R_{\mathrm{f}} 0.88$ (AcOEt/Hept, $1: 1 \mathrm{v} / \mathrm{v}) . M_{\mathrm{w}} / M_{\mathrm{n}} 1.07$.

$\alpha$-Carboxylic acid-polystyrene (2). $\alpha$-Carboxylic acid-polystyrene (2) was synthesized as described by Tu et al. ${ }^{49}$ Polymer product $\mathbf{1}$ (10 g, $0.52 \mathrm{mmol}, 1$ equiv) was dissolved in 1,4-dioxane $(100 \mathrm{~mL})$, after which concentrated $\mathrm{HCl}(5 \mathrm{~mL}, 37 \%)$ was added. The mixture was left to reflux for $18 \mathrm{~h}$ at $110^{\circ} \mathrm{C}$. Progress of deprotection was followed by TLC. Once completed, the reaction mixture was evaporated in vacuo,and subsequently, the solid was dissolved in a minimal amount of DCM. The product was obtained by precipitation in cold $\mathrm{MeOH}$. The precipitate was washed with cold $\mathrm{MeOH}(3 \times)$ and dried in vacuo to yield 2 as a white solid (8.84 g, 88\%). ${ }^{1} \mathrm{H}$ NMR (500 MHz, $\left.\mathrm{CDCl}_{3}\right) \delta 7.98-7.95$ (m, 2H, PS cap ortho), 7.59-7.54 (m, 1H, PS cap para), 7.49-7.45 (m, 2H, PS cap meta), 7.24-6.86 (m, PS arom. ortho and para), $6.58-6.28$ (m, PS arom. meta), $2.30-1.70$ (m, PS backbone $\mathrm{CH}$ ), 1.70-1.17 (m, PS backbone $\left.\mathrm{CH}_{2}\right), 0.87-0.78(\mathrm{~m}$, $6 \mathrm{H}, b) .{ }^{13} \mathrm{C}$ NMR $\left(125 \mathrm{MHz}, \mathrm{CDCl}_{3}\right) \delta 198.6,145.3,137.1,133.1$, 128.7, 128.1, 128.3, 127.7, 125.7, 44.5, 41.8, 40.7, 26.1. $R_{\mathrm{f}} 0.81$ (AcOEt/Hept, 1:1 v/v). $M_{\mathrm{w}} / M_{\mathrm{n}} 1.06$.

$\alpha$-Azide-poly(ethylene glycol)-b-polystyrene (3). Polymer product 2 ( $8.7 \mathrm{~g}, 0.45 \mathrm{mmol}, 1$ equiv), $\alpha$-azide-poly(ethylene glycol)- $\omega$-amine (1.8 g, $0.90 \mathrm{mmol}, 2$ equiv), and DIPEA (0.134 g, $1.04 \mathrm{mmol}, 2.3$ equiv) were dissolved in DMF $(100 \mathrm{~mL})$. The solution was cooled to $0{ }^{\circ} \mathrm{C}$, after which PyBOP $(0.43 \mathrm{~g}, 0.83 \mathrm{mmol}, 1.84$ equiv $)$ was added, and the mixture was allowed to warm to room temperature. The solution was left to stir for $168 \mathrm{~h}$, in which time the reaction was followed by TLC. When finished, the reaction mixture was diluted with DCM and extracted with $\mathrm{NaHCO}_{3}$ (4 wt \% solution) and brine $(2 \times)$. The organic layer was dried over $\mathrm{MgSO}_{4}$ and concentrated in vacuo. The product was precipitated in ice cold $\mathrm{MeOH}$ and subsequently washed with ice cold $\mathrm{MeOH}(3 \times)$. The wet substance was dried in vacuo to yield 3 as a light yellow solid $(6.61 \mathrm{~g}, 69 \%) .{ }^{1} \mathrm{H}$ NMR (500 MHz, CDCl $) \delta 7.70-7.64$ (m, 2H, PS cap ortho), 7.577.52 (m, 1H, PS cap para), 7.49-7.43 (m, 2H, PS cap meta), 7.246.86 (m, PS arom. ortho and para), 6.58-6.28 (m, PS arom. meta), 3.64 (br s, 176H, PEG), 2.30-1.70 (m, PS backbone $\mathrm{CH}$ ), 1.70-1.17 (m, PS backbone $\left.\mathrm{CH}_{2}\right), 1.00-0.93(\mathrm{~m}, 6 \mathrm{H}, b) .{ }^{13} \mathrm{C}$ NMR $(125 \mathrm{MHz}$, $\left.\mathrm{CDCl}_{3}\right) \delta 145.5,139.2,133.1,128.2,128.1,128.0,127.9,125.5,70.6$, 45.3, 42.0, 40.7, 26.1. $M_{\mathrm{w}} / M_{\mathrm{n}} 1.02$.

$\alpha$-Amine-poly(ethylene glycol)-b-polystyrene (4). Polymer product 3 ( $5.5 \mathrm{~g}, 0.263 \mathrm{mmol}$, 1 equiv) was dissolved in dry THF ( 80 $\mathrm{mL})$. Triphenylphosphine $(0.4 \mathrm{~g}, 1.52 \mathrm{mmol}, 5$ equiv) was added to the solution, and the reaction mixture was stirred for $48 \mathrm{~h}$. A total of $100 \mathrm{~mL}$ of water was added, and the mixture was left to reflux at 100 ${ }^{\circ} \mathrm{C}$ for $16 \mathrm{~h}$. Subsequently, the THF was evaporated in vacuo from the reaction mixture, and the remaining solution was alkalinized with $\mathrm{NaOH}$ to $\mathrm{pH}$ 10. The mixture was extracted with DCM, concentrated, and precipitated in ice cold $\mathrm{MeOH}$. The precipitate was washed with ice cold $\mathrm{MeOH}(3 \times)$ to obtain 4 as a white solid (5.4 g, 97\%). ${ }^{1} \mathrm{H}$ NMR (500 MHz, $\left.\mathrm{CDCl}_{3}\right) \delta 7.70-7.64$ (m, 2H, PS cap ortho), 7.57-7.52 (m, 1H, PS cap para), 7.49-7.43 (m, 2H, PS cap meta), 7.24-6.86 (m, PS arom. ortho and para), 6.58-6.28 (m, PS arom. meta), 3.64 (br s, 176H, PEG), 2.30-1.70 (m, PS backbone $\mathrm{CH}$ ), $1.70-1.17$ (m, PS backbone $\left.\mathrm{CH}_{2}\right), 0.96-0.82(\mathrm{~m}, 6 \mathrm{H}, b) .{ }^{13} \mathrm{C}$ NMR $\left(125 \mathrm{MHz}, \mathrm{CDCl}_{3}\right) \delta 145.3,131.9,128.2,128.1,127.9,127.8$, 70.6, 44.1, 42.1, 40.6, 26.4. $M_{\mathrm{w}} / M_{\mathrm{n}} 1.02$.

$\alpha$-Azide-poly(ethylene glycol)-b-polylactic acid (5). $\alpha$-Azidepoly(ethylene glycol)- $b$-polylactic acid (5) was prepared as described by Sherck et al. ${ }^{50} \mathrm{~N}_{3}-\mathrm{PEG}_{44}-\mathrm{OH}(2.65 \mathrm{~g}, 1.2 \mathrm{mmol}, 1$ equiv) and
D,L-Lactide ( $15.4 \mathrm{~g}, 107.1 \mathrm{mmol}, 188$ equiv) were dissolved in dry toluene $(150 \mathrm{~mL})$. The solution was concentrated, and the residual solvent was removed using a high vacuum. The solid was dissolved in dry DCM $(130 \mathrm{~mL})$ under argon. To this solution, DBU $(188 \mu \mathrm{L}, 0.6$ mmol, 0.5 equiv) was added. The mixture was stirred and heated to $40{ }^{\circ} \mathrm{C}$ for $2 \mathrm{~h}$. Afterward, the reaction mixture was concentrated in vacuo and subsequently precipitated in ice cold $\mathrm{Et}_{2} \mathrm{O}(2 \times)$. The precipitate was dissolved in minimal 1,4-dioxane and lyophilized to yield 5 as a white solid $(9.10 \mathrm{~g}, 91 \%) .{ }^{1} \mathrm{H}$ NMR $\left(500 \mathrm{MHz}, \mathrm{CDCl}_{3}\right) \delta$ 5.33-4.49 (m, PDLLA CH), 3.57 (br s, 176H, PEG), 1.76-1.32 (m, PDLLA $\left.\mathrm{CH}_{3}\right) .{ }^{13} \mathrm{C}$ NMR $\left(125 \mathrm{MHz}, \mathrm{CDCl}_{3}\right) \delta 206.9,169.6,70.6$, 69.0, 16.6. $M_{\mathrm{w}} / M_{\mathrm{n}} 1.09$.

$\alpha$-Amine-poly(ethylene glycol)-b-polylactic acid (6). Polymer product $5(9.0 \mathrm{~g}, 0.6 \mathrm{mmol}, 1$ equiv) was dissolved in dry THF (70 $\mathrm{mL})$. Triphenylphosphine $(0.47 \mathrm{~g}, 1.8 \mathrm{mmol}, 3$ equiv) dissolved in dry THF $(5 \mathrm{~mL})$ was added to the solution and the reaction mixture was stirred for $48 \mathrm{~h}$ at $50^{\circ} \mathrm{C}$. A total of $50 \mathrm{~mL}$ of water was added, and the mixture was left to reflux at $100{ }^{\circ} \mathrm{C}$ for $16 \mathrm{~h}$. Subsequently, the THF was evaporated in vacuo from the reaction mixture and the remaining solution was alkalinized with $\mathrm{NaOH}$ to $\mathrm{pH} 10$. The mixture was extracted with DCM. The water layer was reduced in vacuo, concentrated, and precipitated in ice cold $\mathrm{Et}_{2} \mathrm{O}$. The precipitate was dissolved in minimal 1,4-dioxane and lyophilized to yield 6 as a white solid (7.9 g, 87\%). ${ }^{1} \mathrm{H}$ NMR (500 MHz, $\left.\mathrm{CDCl}_{3}\right) \delta 5.31-4.41(\mathrm{~m}$, PDLLA CH), 3.64 (br s, 176H, PEG), 1.63-1.38 (m, PDLLA CH ${ }_{3}$ ). ${ }^{13} \mathrm{C} \mathrm{NMR}\left(125 \mathrm{MHz}, \mathrm{CDCl}_{3}\right) \delta 206.9,169.6,70.6,69.0,16.6 . M_{\mathrm{w}} / M_{\mathrm{n}}$ 1.03.

$\alpha$-Amine-poly(ethylene glycol)-b-polylactic acid-TBS (7). Polymer product 6 ( $7.5 \mathrm{~g}, 0.5 \mathrm{mmol}, 1$ equiv) was dissolved in dry DCM $(20 \mathrm{~mL})$ and degassed for $15 \mathrm{~min} . \mathrm{Et}_{3} \mathrm{~N}(0.5 \mathrm{~mL}, 3.6 \mathrm{mmol}, 7$ equiv), TBDMSCl (492 mg, $3.26 \mathrm{mmol}, 7$ equiv), and DMAP ( $3.8 \mathrm{mg}, 0.03$ mmol; 0.06 equiv) were added to the solution. The reaction mixture was stirred for $16 \mathrm{~h}$ at $21^{\circ} \mathrm{C}$ under an argon atmosphere. The mixture was concentrated in vacuo and precipitated in ice cold $\mathrm{Et}_{2} \mathrm{O}$. The precipitate was dissolved in minimal 1,4-dioxane and lyophilized to yield 7 as a white solid $(5.5 \mathrm{~g}, 73 \%) .{ }^{1} \mathrm{H}$ NMR $\left(400 \mathrm{MHz}, \mathrm{CDCl}_{3}\right) \delta$ 5.78-4.19 (m, PDLLA CH), 3.64 (br s, 176H, PEG), 1.63-1.38 (m, PDLLA $\left.\mathrm{CH}_{3}\right), 0.92\left(\mathrm{~s}, 9 \mathrm{H}, \mathrm{C}\left(\mathrm{CH}_{3}\right)_{3}\right), 0.15\left(\mathrm{~s}, 6 \mathrm{H}, \mathrm{Si}\left(\mathrm{CH}_{3}\right)_{2}\right) .{ }^{13} \mathrm{C}$ NMR $\left(101 \mathrm{MHz}, \mathrm{CDCl}_{3}\right) \delta 206.9,169.6,70.6,69.0,16.7,16.6,8.6$, 1.0. $M_{\mathrm{w}} / M_{\mathrm{n}} 1.03$.

$\alpha$-Acetylthiol-poly(ethylene glycol) ATRP initiator (8). $\alpha$-Acetylthiol-poly(ethylene glycol) ATRP initiator (8) was prepared as described by $\mathrm{Tu}$ et al. ${ }^{49} \alpha$-Acetylthiol-poly(ethylene glycol) (250 $\mathrm{mg}, 125 \mu \mathrm{mol}, 1$ equiv) was dissolved in dry THF $(25 \mathrm{~mL})$ in a flamed-dried Schlenk flask. After adding $\mathrm{Et}_{3} \mathrm{~N}(52 \mu \mathrm{L}, 375 \mu \mathrm{mol}, 3$ equiv), the mixture was cooled to $0{ }^{\circ} \mathrm{C} . \alpha$-bromoisobutyryl bromide (30.8 $\mu \mathrm{L}, 250 \mu \mathrm{mol}, 2$ equiv) was added dropwise. After addition, the resulting solution was stirred for $24 \mathrm{~h}$ while slowly warming to $21^{\circ} \mathrm{C}$. After the reaction, the white precipitate was filtered off and the solution was concentrated. The polymer was precipitated in ice-cold diethyl ether $(2 \times)$ and dried in vacuo to obtain 8 as a white solid (184 $\mathrm{mg}, 73 \%) .{ }^{1} \mathrm{H}$ NMR (500 MHz, $\left.\mathrm{CDCl}_{3}\right) \delta 4.37-4.28(\mathrm{~m}, 2 \mathrm{H}$, $\left.\mathrm{CH}_{2} \mathrm{CH}_{2} \mathrm{OC}(\mathrm{O}) \mathrm{C}\left(\mathrm{CH}_{3}\right)_{2} \mathrm{Br}\right), 3.77-3.72\left(\mathrm{~m}, 2 \mathrm{H}, \mathrm{CH}_{2} \mathrm{CH}_{2} \mathrm{OC}(\mathrm{O})-\right.$ $\left.\mathrm{C}\left(\mathrm{CH}_{3}\right)_{2} \mathrm{Br}\right), 3.64$ (br s, $\left.172 \mathrm{H}, \mathrm{PEG}\right), 3.09(\mathrm{t}, J=6.5 \mathrm{~Hz}, 6 \mathrm{H}$, $\left.\mathrm{AcSCH}_{2}\right), 2.34(\mathrm{~s}, 3 \mathrm{H}$, acetyl $), 1.94\left(\mathrm{~s}, 6 \mathrm{H}, \mathrm{C}\left(\mathrm{CH}_{3}\right)_{2} \mathrm{Br}\right) .{ }^{13} \mathrm{C}$ NMR $\left(125 \mathrm{MHz}, \mathrm{CDCl}_{3}\right) \delta 195.5,171.6,68.8,65.1,70.5,28.9,30.8,30.6$.

Synthesis of Functionalized Polymers. General Procedure for Coupling of Carboxylic Acid and NHS Derivatives to 4 (Method A). Polymer product $4(250 \mathrm{mg}, 10.3 \mu \mathrm{mol}, 1$ equiv), DMAP $(12.5 \mathrm{mg}$, $103 \mu \mathrm{mol}, 10$ equiv), and carboxylic acid or NHS derivative (103 $\mu \mathrm{mol}, 10$ equiv) were dissolved in DCM $(10 \mathrm{~mL})$. EDC (19.6 mg, $103 \mu \mathrm{mol}, 10$ equiv) was added to the reaction mixture and was stirred at $21{ }^{\circ} \mathrm{C}$. The progress of the reaction was followed by the Kaiser test. ${ }^{46}$ Upon confirming a negative Kaiser test (>99\% reacted), the reaction mixture was concentrated in vacuo and precipitated in ice cold $\mathrm{MeOH}$. The solid was subsequently washed with ice cold $\mathrm{MeOH}$ $(2 \times)$ and water $(1 \times)$. The polymer product was dried overnight in vacuo to yield the functionalized PEG- $b$-PS polymer. NMR shifts are equal to 4, with signals from the functional groups reported when visible. 
General Procedure for Coupling of Carboxylic Acid and NHS Derivatives to 7 (Method B). The carboxylic acid or NHS derivative (130 $\mu \mathrm{mol}, 10$ equiv) and DIPEA (20 $\mu \mathrm{L}, 110 \mu \mathrm{mol}, 9$ equiv) were dissolved in DCM $(1 \mathrm{~mL})$, after which the solution was cooled to 0 ${ }^{\circ} \mathrm{C}$. PyBOP (64.1 mg, $110 \mu \mathrm{mol}, 9$ equiv) was dissolved in DCM $(0.5$ $\mathrm{mL})$, added dropwise to the cooled solution and subsequently stirred for $1 \mathrm{~h}$. Then, polymer product 7 ( $200 \mathrm{mg}, 13.0 \mu \mathrm{mol}, 1$ equiv) was dissolved in DCM (2 mL) and added to the stirring solution and allowed to slowly warm up to $21^{\circ} \mathrm{C}$. The progress of the reaction was followed by the Kaiser test. ${ }^{46}$ Upon confirming a negative Kaiser test ( $>99 \%$ reacted), the reaction mixture was concentrated in vacuo and precipitated in ice cold $\mathrm{Et}_{2} \mathrm{O}$. The solid was subsequently dissolved in 1,4-dioxane and lyophilized to yield the functionalized PEG- $b$-PDLLA polymer. NMR shifts are equal to 7 , with signals from the functional groups reported when visible.

General Procedure for Coupling of Halide Derivatives to 4 and 7 (Method C). Polymer product 4 (250 mg, $10.3 \mu \mathrm{mol}$, 1 equiv) or 7 (200 mg, $13.0 \mu \mathrm{mol}, 1$ equiv) was dissolved in DCM $(2 \mathrm{~mL})$, after which $\mathrm{Et}_{3} \mathrm{~N}$ (20 equiv) was added to the solution. The acyl halide derivative (10 equiv) dissolved in DCM $(1 \mathrm{~mL})$ was added dropwise, and the mixture was stirred at $21^{\circ} \mathrm{C}$. The progress of the reaction was followed by the Kaiser test. ${ }^{46}$ Upon confirming a negative Kaiser test ( $>99 \%$ reacted), the reaction mixture was concentrated in vacuo and precipitated in ice cold $\mathrm{MeOH}$ (PEG- $b$-PS) or $\mathrm{Et}_{2} \mathrm{O}$ (PEG- $b$-PDLLA) and washed with the appropriate solvent $(2 \times)$. The PEG- $b$-PS product was dried overnight in vacuo to yield the functionalized PEG$b$-PS polymer. The PEG- $b$-PDLLA product was dissolved in 1,4dioxane and lyophilized to yield the functionalized PEG- $b$-PDLLA polymer. NMR shifts are equal to 4 or 7 , with signals from the functional groups reported when visible.

$\alpha$-Alkyne-poly(ethylene glycol)-b-polystyrene (4a). Method A: 4pentynoic acid $(6.67 \mathrm{mg})$; Yield: $66 \%$. The alkyne peaks could not be seen on the NMR spectrum.

$\alpha$-Alkyne-poly(ethylene glycol)-b-polylactic acid (7a). Method C: Propargyl chloroformate $(12.7 \mu \mathrm{L})$; Yield: 66\%. Handle ${ }^{1} \mathrm{H}$ NMR shifts: ${ }^{1} \mathrm{H}$ NMR $\left(500 \mathrm{MHz}, \mathrm{CDCl}_{3}\right) \delta 2.77(\mathrm{~s}, 1 \mathrm{H})$.

$\alpha$-Dibenzocyclooctyne-poly(ethylene glycol)-b-polystyrene (4b). Method A: Dibenzocyclooctyne- $N$-hydroxysuccinimidyl ester $(41.2$ $\mathrm{mg}$ ); Yield: $62 \%$. Handle ${ }^{1} \mathrm{H}$ NMR shifts: ${ }^{1} \mathrm{H}$ NMR $(500 \mathrm{MHz}$, $\left.\mathrm{CDCl}_{3}\right) \delta 7.73-7.65(\mathrm{~m}, 1 \mathrm{H}$, aromatic $), 5.23-5.12(\mathrm{~m}, 2 \mathrm{H}$, cyclooctane $\left.\mathrm{CH}_{2}\right), 3.11-3.04\left(\mathrm{~m}, 1 \mathrm{H}, \mathrm{NHC}(\mathrm{O}) \mathrm{CH}_{2} \mathrm{CH}_{2} \mathrm{C}(\mathrm{O}) \mathrm{N}\right)$, 2.88-2.80 (m, $\left.1 \mathrm{H}, \mathrm{NHC}(\mathrm{O}) \mathrm{CH}_{2} \mathrm{CH}_{2} \mathrm{C}(\mathrm{O}) \mathrm{N}\right), 2.69-2.60(\mathrm{~m}, 1 \mathrm{H}$, $\left.\mathrm{NHC}(\mathrm{O}) \mathrm{CH}_{2} \mathrm{CH}_{2} \mathrm{C}(\mathrm{O}) \mathrm{N}\right)$.

$\alpha$-Dibenzocyclooctyne-poly(ethylene glycol)-b-polylactic acid (7b). Method B: Dibenzocyclooctyne- $N$-hydroxysuccinimidyl ester (52 mg); Yield: 70\%. Handle ${ }^{1} \mathrm{H}$ NMR shifts: ${ }^{1} \mathrm{H}$ NMR $(500 \mathrm{MHz}$, $\left.\mathrm{CDCl}_{3}\right) \delta 7.86(\mathrm{~d}, J=7.9 \mathrm{~Hz}, 4 \mathrm{H}$, aromatic), $7.68(\mathrm{~d}, J=8.1 \mathrm{~Hz}, 4 \mathrm{H}$, aromatic), $2.79-2.70\left(\mathrm{~m}, 4 \mathrm{H}, \mathrm{NHC}(\mathrm{O}) \mathrm{CH}_{2} \mathrm{CH}_{2} \mathrm{C}(\mathrm{O}) \mathrm{N}\right)$.

$\alpha$-Aminooxy-poly(ethylene glycol)-b-polystyrene (4c). Method A: (Boc-aminooxy) acetic acid $(19.5 \mathrm{mg})$. The product was then dissolved in DCM $(2 \mathrm{~mL})$. Trifluoroacetic acid $(11.9 \mathrm{mg}, 103 \mu \mathrm{mol}$, 10 equiv) was added slowly in the solution. Subsequently, the reaction mixture was stirred for $16 \mathrm{~h}$. Workup then proceeded according to Method A. Total yield: $57 \%$. The aminooxy peaks could not be seen on the NMR spectrum.

$\alpha$-Aminooxy-poly(ethylene glycol)-b-polylactic acid (7c). Method B: (Boc-aminooxy) acetic acid $(24.6 \mathrm{mg})$. The product was then dissolved in DCM $(2 \mathrm{~mL})$. Trifluoroacetic acid $(15.0 \mathrm{mg}, 130 \mu \mathrm{mol}$, 10 equiv) was added slowly in the solution. Subsequently, the reaction mixture was stirred for $16 \mathrm{~h}$. Workup then proceeded according to Method B. Total yield: $28 \%$. Handle ${ }^{1} \mathrm{H}$ NMR shifts: ${ }^{1} \mathrm{H}$ NMR (500 $\left.\mathrm{MHz}, \mathrm{DMSO}-d_{6}\right) \delta 9.40\left(\mathrm{~s}, 2 \mathrm{H}, \mathrm{NH}_{2}\right)$.

$\alpha$-Bromine-poly(ethylene glycol)-b-polystyrene (4d). Method C: $\alpha$-bromoisobutyryl bromide $(12.6 \mu \mathrm{L})$; Yield: $91 \%$. Handle ${ }^{1} \mathrm{H}$ NMR shifts: ${ }^{1} \mathrm{H}$ NMR $\left(500 \mathrm{MHz}, \mathrm{CDCl}_{3}\right) \delta 1.94(\mathrm{~s}, 6 \mathrm{H})$.

$\alpha$-Bromine-poly(ethylene glycol)-b-polylactic acid (7d). Method C: $\alpha$-bromoisobutyryl bromide $(16.5 \mu \mathrm{L})$; Yield: $71 \%$. Handle ${ }^{1} \mathrm{H}$ NMR shifts: ${ }^{1} \mathrm{H}$ NMR $\left(500 \mathrm{MHz}, \mathrm{CDCl}_{3}\right) \delta 1.94(\mathrm{~s}, 6 \mathrm{H})$.
$\alpha$-Maleimide-poly(ethylene glycol)-b-polystyrene (4e). Method A: 3-maleimidopropionic acid (17.2 mg); Yield: $84 \%$. The alkene peaks could not be seen on the NMR spectrum.

$\alpha$-Maleimide-poly(ethylene glycol)-b-polylactic acid (7e). Method B: 3-maleimidopropionic acid (21.7 mg); Yield: 63\%. The alkene peaks could not be seen on the NMR spectrum.

$\alpha$-2-[4-(6-Methyl-1,2,4,5-tetrazine-3-yl)phenyl]-poly(ethylene glycol)-b-polystyrene (4f). Method A: 2-[4-(6-methyl-1,2,4,5-tetrazine-3-yl)phenyl]acetic acid $(23.7 \mathrm{mg})$; Yield: $88 \%$. Handle ${ }^{1} \mathrm{H}$ NMR shifts: ${ }^{1} \mathrm{H}$ NMR $\left(500 \mathrm{MHz}, \mathrm{CDCl}_{3}\right) \delta 8.57-8.19$ (m, 4H, aromatic), $3.10\left(\mathrm{~s}, 3 \mathrm{H}, \mathrm{CH}_{3}\right)$.

$\alpha$-2-[4-(6-Methyl-1,2,4,5-tetrazine-3-yl)phenyl]-poly(ethylene glycol)-b-polylactic acid (7f). Method B: 2-[4-(6-methyl-1,2,4,5tetrazine-3-yl)phenyl] acetic acid $(29.9 \mathrm{mg})$; Yield: $86 \%$. Handle ${ }^{1} \mathrm{H}$ NMR shifts: ${ }^{1} \mathrm{H}$ NMR $\left(500 \mathrm{MHz}, \mathrm{CDCl}_{3}\right) \delta 8.55-7.35(\mathrm{~m}, 4 \mathrm{H}$, aromatic)

$\alpha$-Oxobutan-poly(ethylene glycol)-b-polystyrene (4g). Method A: 3-(1,3-dioxolan-2-yl)propanoic acid $(60 \mathrm{mg})$. After the coupling was determined to be successful, aq. $\mathrm{HCl}$ was added until the $\mathrm{pH}$ was $<1$. The reaction mixture was stirred for an additional $24 \mathrm{~h}$. Workup then proceeded according to Method A. Yield: 97\%. Handle ${ }^{1} \mathrm{H}$ NMR shifts: ${ }^{1} \mathrm{H}$ NMR (500 MHz, THF- $\left.d_{8}\right) \delta 9.57$ (s, $1 \mathrm{H}$, aldehyde).

$\alpha$-Oxobutan-poly(ethylene glycol)-b-polylactic acid (7g). Method B: 3-(1,3-dioxolan-2-yl)propanoic acid $(75.7 \mathrm{mg})$. After the coupling was determined to be successful, aq. $\mathrm{HCl}$ was added until the $\mathrm{pH}$ was 4 . The reaction mixture was stirred for an additional $24 \mathrm{~h}$. Workup then proceeded according to Method B. Yield: 72\%. Handle ${ }^{1} \mathrm{H}$ NMR shifts: ${ }^{1} \mathrm{H}$ NMR $\left(500 \mathrm{MHz}, \mathrm{CDCl}_{3}\right) \delta 9.82(\mathrm{~s}, 1 \mathrm{H}$, aldehyde).

$\alpha$-Hydroxyimino butanamide-poly(ethylene glycol)-b-polystyrene (4h). Compound $\mathbf{4 g}$ (500 mg, $20.5 \mu \mathrm{mol}, 1$ equiv ) was dissolved in DCM $(8 \mathrm{~mL})$, after which hydroxalamine $\mathrm{HCl}(14.2 \mathrm{mg}, 205 \mu \mathrm{mol}$, 10 equiv) and $\mathrm{Et}_{3} \mathrm{~N}$ ( $41.5 \mathrm{mg}, 410 \mu \mathrm{mol}, 20$ equiv) were added to the mixture. The reaction mixture was left to stir for $16 \mathrm{~h}$. Workup then proceeded according to Method A. Yield: $86 \%$. The hydroximino peaks could not be seen on the NMR spectrum.

$\alpha$-Hydroxyimino butanamide -poly(ethylene glycol)-b-polylactic acid (7h). Compound $7 \mathrm{~g}(50 \mathrm{mg}, 3.25 \mu \mathrm{mol}, 1$ equiv), was dissolved in DCM (4 mL), after which hydroxalamine $\mathrm{HCl}(2.3 \mathrm{mg}, 32.5 \mu \mathrm{mol}$, 10 equiv) and $\mathrm{Et}_{3} \mathrm{~N}$ ( $6.6 \mathrm{mg}, 65 \mu \mathrm{mol}, 20$ equiv) were added. The solution was stirred for $16 \mathrm{~h}$. Workup then proceeded according to Method B. Yield: $71 \%$. The hydroximino peaks could not be seen on the NMR spectrum.

$\alpha$-Hydrazineylidene butanamide-poly(ethylene glycol)-b-polystyrene (4i). Compound $4 \mathrm{~g}$ (200 mg, $8.2 \mu \mathrm{mol}, 1$ equiv) was dissolved in THF (4 mL), after which hydrazine hydrate $(4.1 \mathrm{mg}, 82$ $\mu$ mol, 10 equiv) was added. The solution was stirred for $16 \mathrm{~h}$. Workup then proceeded according to Method A. Yield: $76 \%$. The hydrazine peaks could not be seen on the NMR spectrum.

$\alpha$-Hydrazineylidene butanamide -poly(ethylene glycol)-b-polylactic acid (7i). Compound $7 \mathrm{~g}(50 \mathrm{mg}, 3.25 \mu \mathrm{mol}$, 1 equiv), was dissolved in THF $(4 \mathrm{~mL})$, after which hydrazine hydrate $(1.6 \mathrm{mg}, 32.5$ $\mu$ mol, 10 equiv) was added. The solution was stirred for $16 \mathrm{~h}$. Workup then proceeded according to Method B. Yield: 54\%. The hydrazine peaks could not be seen on the NMR spectrum.

$\alpha$-Norbornene-poly(ethylene glycol)-b-polystyrene (4j). Method A: 5-norbornene-2-carboxylic acid (14.1 mg); Yield: 93\%. Handle ${ }^{1} \mathrm{H}$ NMR shifts: ${ }^{1} \mathrm{H}$ NMR $\left(500 \mathrm{MHz}, \mathrm{CDCl}_{3}\right) \delta 6.13(\mathrm{dd}, J=5.7,3.1 \mathrm{~Hz}$, $1 \mathrm{H}$, alkene), $5.94(\mathrm{dd}, J=5.7,2.8 \mathrm{~Hz}, 1 \mathrm{H}$, alkene), $3.20-3.10(\mathrm{~m}, 1 \mathrm{H}$, $\mathrm{HNC}(\mathrm{O}) \mathrm{CHCH}), 2.91(\mathrm{dt}, J=8.6,3.5 \mathrm{~Hz}, 1 \mathrm{H}, \mathrm{HNC}(\mathrm{O}) \mathrm{CH}), 2.84$ $\left(\mathrm{s}, 1 \mathrm{H}, \mathrm{HNC}(\mathrm{O}) \mathrm{CHCH}_{2} \mathrm{CH}\right), 1.84-1.33(\mathrm{~m}, 2 \mathrm{H}, \mathrm{HNC}(\mathrm{O})-$ $\left.\mathrm{CHCH}_{2}\right), 1.37-1.22(\mathrm{~m}, 2 \mathrm{H}$, bridge).

$\alpha$-Norbornene-poly(ethylene glycol)-b-polylactic acid (7j). Method B: 5-norbornene-2-carboxylic acid (17.8 mg); Yield: 70\%. Handle ${ }^{1} \mathrm{H}$ NMR shifts: ${ }^{1} \mathrm{H}$ NMR $\left(500 \mathrm{MHz}, \mathrm{CDCl}_{3}\right) \delta 6.28-5.88(\mathrm{~m}, 2 \mathrm{H}$, alkene).

$\alpha$-GlyGlyGly-poly(ethylene glycol)-b-polystyrene (4k). Method A: $\mathrm{N}$-tert-Butoxycarbonyl-glycyl-glycyl-glycine was prepared as described by Naumovich et al. ${ }^{51}$ and subsequently used $(37 \mathrm{mg})$. After the coupling was determined to be successful, aq. $\mathrm{HCl}$ was added until the 
Scheme 1. Retrosynthesis of the Functionalized PEG- $b$-PS and PEG- $b$-PDLLA Polymers

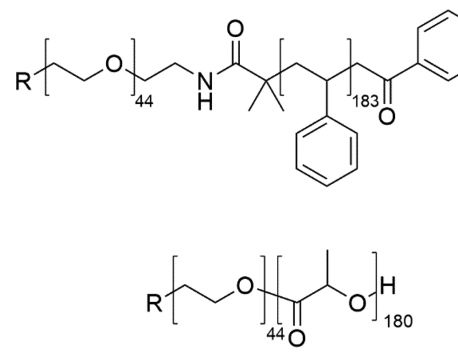

$\mathrm{pH}$ was $<1$. The reaction mixture was stirred for an additional $24 \mathrm{~h}$. Workup then proceeded according to Method A. Yield: $83 \%$. Handle ${ }^{1} \mathrm{H}$ NMR shifts: ${ }^{1} \mathrm{H}$ NMR $\left(500 \mathrm{MHz}, \mathrm{CDCl}_{3}\right) \delta 3.96-3.80(\mathrm{~m}, 6 \mathrm{H}$, Gly backbone).

$\alpha$-GlyGlyGly-poly(ethylene glycol)-b-polylactic acid (7k). Method B: N-tert-Butoxycarbonyl-glycyl-glycyl-glycine was prepared as described by Naumovich et al. ${ }^{51}$ and subsequently used (46.7 mg). After the coupling was determined to be successful, aq. $\mathrm{HCl}$ was added until the $\mathrm{pH}$ was 5 . The reaction mixture was stirred for an additional $24 \mathrm{~h}$. Workup then proceeded according to Method B. Yield: $85 \%$. Handle ${ }^{1} \mathrm{H}$ NMR shifts: ${ }^{1} \mathrm{H}$ NMR (500 $\left.\mathrm{MHz}, \mathrm{CDCl}_{3}\right) \delta$ 0.96-3.80 (m, 6H, Gly backbone).

$\alpha$-FITC-poly(ethylene glycol)-b-polystyrene (4I). Fluorescein 5isothiocyanate ( $8 \mathrm{mg}, 20.6 \mu \mathrm{mol}, 2$ equiv) and $4(250 \mathrm{mg}, 10.3 \mu \mathrm{mol}$, 1 equiv) were dissolved in DMSO $(0.5 \mathrm{~mL}) . \mathrm{Et}_{3} \mathrm{~N}(3 \mu \mathrm{L}, 20.6 \mu \mathrm{mol}, 2$ equiv) was added, and the mixture was stirred in the dark for $4 \mathrm{~h}$. The solvent was removed in vacuo. Workup then proceeded according to Method A. Yield: $81 \%$. The FITC peaks could not be seen on the NMR spectrum. UV-vis $\lambda \max \left(\mathrm{CHCl}_{3}\right) / \mathrm{nm} \mathrm{257,} 461$ and 486 .

$\alpha$-FITC -poly(ethylene glycol)-b-polylactic acid (7I). Fluorescein 5-isothiocyanate $(19.5 \mathrm{mg}, 50 \mu \mathrm{mol}, 2$ equiv) and $7(200 \mathrm{mg}, 25$ $\mu$ mol, 1 equiv) were dissolved in DMSO $(0.5 \mathrm{~mL}) . \mathrm{Et}_{3} \mathrm{~N}(7.4 \mu \mathrm{L}, 50$ $\mu$ mol, 2 equiv) was added, and the mixture was stirred in the dark for $4 \mathrm{~h}$. The solvent was removed in vacuo. Workup then proceeded according to Method B. Yield: $50 \%$. The FITC peaks could not be seen on the NMR spectrum. UV-vis $\lambda \max \left(\mathrm{CHCl}_{3}\right) / \mathrm{nm} 462$ and 488.

$\alpha$-Acryolyl-poly(ethylene glycol)-b-polystyrene $(4 \mathrm{~m})$. Method C: Acryloyl chloride $(7.7 \mu \mathrm{L})$; Yield: 69\%. Handle ${ }^{1} \mathrm{H}$ NMR shifts: ${ }^{1} \mathrm{H}$ NMR (500 MHz, $\left.\mathrm{CDCl}_{3}\right) \delta 6.64(\mathrm{~d}, J=16.5 \mathrm{~Hz}, 1 \mathrm{H}, \mathrm{CHH}=$ $\mathrm{CHC}(\mathrm{O}) \mathrm{NH}), 6.18(\mathrm{~d}, J=10.2 \mathrm{~Hz}, 1 \mathrm{H}, \mathrm{CH} H=\mathrm{CHC}(\mathrm{O}) \mathrm{NH}), 6.35$ (dd, $J=16.3,10.3 \mathrm{~Hz}, 1 \mathrm{H}, \mathrm{CHH}=\mathrm{CHC}(\mathrm{O}) \mathrm{NH})$.

$\alpha$-Acryolyl-poly(ethylene glycol)-b-polylactic acid (7m). Method C: Acryloyl chloride $(9.8 \mu \mathrm{L})$; Yield: $99 \%$. Handle ${ }^{1} \mathrm{H}$ NMR shifts: ${ }^{1} \mathrm{H}$ NMR (500 MHz, $\left.\mathrm{CDCl}_{3}\right) \delta 6.48(\mathrm{~d}, J=16.6 \mathrm{~Hz}, 1 \mathrm{H}, \mathrm{CHH}=$ $\mathrm{CHC}(\mathrm{O}) \mathrm{NH}), 6.18(\mathrm{~d}, J=10.2 \mathrm{~Hz}, 1 \mathrm{H}, \mathrm{CH}=\mathrm{CHC}(\mathrm{O}) \mathrm{NH}), 5.91$ (dd, $J=16.5,10.2 \mathrm{~Hz}, 1 \mathrm{H}, \mathrm{CHH}=\mathrm{CHC}(\mathrm{O}) \mathrm{NH})$.

$\alpha$-Acetylthiol-poly(ethylene glycol)-polystyrene (4n). $\mathrm{CuBr}$ (45 $\mathrm{mg}, 0.32 \mathrm{mmol}, 3.2$ equiv) was charged in a flame-dried Schlenk flask. PMDETA (66 $\mu \mathrm{L}, 0.32 \mathrm{mmol}, 3.2$ equiv) in anisole $(0.5 \mathrm{~mL})$ was added to the flask, after which it was vigorously stirred for $15 \mathrm{~min}$. Styrene ( $5 \mathrm{~mL}, 43.6 \mathrm{mmol}, 436$ equiv) was added and the mixture was degassed for $15 \mathrm{~min}$. The mixture was cooled to $0{ }^{\circ} \mathrm{C}$ and $8(215 \mathrm{mg}$, $0.10 \mathrm{mmol}, 1$ equiv) was added after which the mixture was degassed for another $15 \mathrm{~min}$. The mixture was heated to $90{ }^{\circ} \mathrm{C}$, and the progress of polymerization was followed by ${ }^{1} \mathrm{H}$ NMR. When the desired molecular length was obtained, 1-phenyl-1-trimethylsiloxyethene $(1.91 \mathrm{~mL}, 9.28 \mathrm{mmol}, 92.8$ equiv) was added to terminate the reaction and left to stir for $2 \mathrm{~h}$. Subsequently, the reaction mixture was diluted with DCM, extracted with $50 \mathrm{mM}$ EDTA solution twice and once with brine. The washed organic fraction was dried over $\mathrm{MgSO}_{4}$ and concentrated by rotary evaporation. The concentrate was precipitated in ice cold $\mathrm{MeOH}$ and subsequently washed with cold $\mathrm{MeOH}(3 \times)$ and dried in vacuo to obtain $\mathbf{4 n}$ as a white solid. Yield:
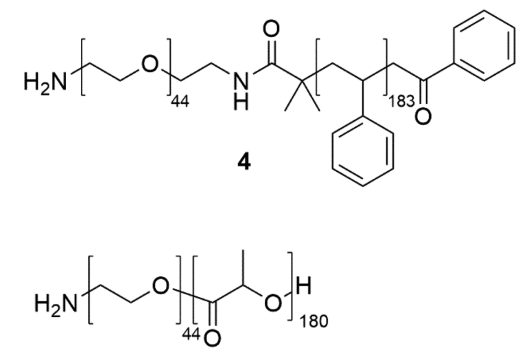

7

85\%. Handle ${ }^{1} \mathrm{H}$ NMR shifts: ${ }^{1} \mathrm{H}$ NMR (500 MHz, $\left.\mathrm{CDCl}_{3}\right) \delta 2.33$ (s, $3 \mathrm{H}$, acetyl). $M_{\mathrm{W}} / M_{\mathrm{n}} 1.07$.

$\alpha$-Thiol-poly(ethylene glycol)-polystyrene (40). Compound 4n (300 mg, $14.3 \mu \mathrm{mol}, 1$ equiv) was dissolved in a $\mathrm{MeOH}(25 \mathrm{~mL}$ ) and DCM $(35 \mathrm{~mL})$ mixture. $\mathrm{K}_{2} \mathrm{CO}_{3}(8 \mathrm{mg}, 57.2 \mu \mathrm{mol}, 4$ equiv) was added to the solution. The mixture was stirred for $16 \mathrm{~h}$ at $21{ }^{\circ} \mathrm{C}$. Subsequently the reaction mixture was diluted with AcOEt, extracted with $1 \mathrm{M} \mathrm{HCl}$ solution twice and once with brine. The washed organic fraction was dried over $\mathrm{MgSO}_{4}$ and concentrated by rotary evaporation. The concentrate was precipitated in ice cold $\mathrm{MeOH}$ and subsequently washed with cold $\mathrm{MeOH}(3 \times)$ and dried in vacuo to obtain 40 as a white solid. Yield: $83 \%$. The sulfur peaks could not be seen on the NMR spectrum.

Synthesis of 3-Azido-7-hydroxycoumarin. 3-Azido-7-hydroxycoumarin was prepared as described by Yi et al. ${ }^{52}$ with a yield of $15 \%$.

Preparation of PEG- $b$-PS Polymersomes. Modified from a

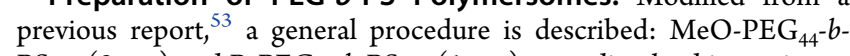
$\mathrm{PS}_{170}(9 \mathrm{mg})$ and R-PEG $44-b-\mathrm{PS}_{183}(1 \mathrm{mg})$ were dissolved in a mixture of THF and 1,4-dioxane ( $1 \mathrm{~mL}, 4: 1$ by volume) in a $15 \mathrm{~mL}$ capped vial with a magnetic stirrer. After dissolving the solution for $0.5 \mathrm{~h}$ at 21 ${ }^{\circ} \mathrm{C}$, a syringe pump equipped with a syringe and a needle was used to deliver Milli-Q water with a rate of $1 \mathrm{~mL} / \mathrm{h}$ for $0.5 \mathrm{~h}$ via a rubber septum, while vigorously stirring the mixture (900 rpm). When finishing the water addition, $10 \mathrm{~mL}$ of Milli-Q was added to the suspension, which ensured a rapid quenching of the PS domain within the bilayer of the polymersomes. The polymersomes were spun down via centrifuge and washed with Milli-Q a total of three times.

Preparation of PEG- $\boldsymbol{b}$-PDLLA Polymersomes. MeO-PEG $\mathrm{M}_{22}-\boldsymbol{b}$ PDLLA $_{94}(9 \mathrm{mg})$ and R-PEG $44-b-$ PDLLA $_{183}(1 \mathrm{mg})$ were dissolved in a mixture of THF and 1,4-dioxane ( $1 \mathrm{~mL}, 4: 1$ by volume) in a $15 \mathrm{~mL}$ capped vial with a magnetic stirrer. After mixing the solution for $0.5 \mathrm{~h}$ at $21{ }^{\circ} \mathrm{C}$, an equivalent Milli-Q water was added via a syringe pump with a rate of $1 \mathrm{~mL} / \mathrm{h}$ for $1 \mathrm{~h}$ via a rubber septum, while vigorously stirring the mixture $(900 \mathrm{rpm})$. Afterward, the samples were dialyzed against $1 \mathrm{~L}$ of Milli-Q water for $24 \mathrm{~h}$ with a solution change after $1 \mathrm{~h}$ at $4{ }^{\circ} \mathrm{C}$ (membrane cut-off $12-14 \mathrm{kDa}$ ).

Click Reaction on DBCO-PEG- $b$-PS Polymersomes. A total of $20 \mu \mathrm{L}$ of concentrated DBCO-PEG- $b$-PS polymersomes were diluted in $1 \mathrm{~mL}$ of Milli-Q water. 3-Azido-7-hydroxycoumarin $(0.5 \mathrm{mg})$ was added to the solution and the mixture was stirred for $16 \mathrm{~h}$ in the dark before measuring fluorescence.

\section{RESULTS AND DISCUSSION}

Synthesis of the Base Polymer. From a retrosynthetic point of view, almost any functionalized group can be covalently attached to the polymers via an amide coupling to compounds 4 and 7 (Scheme 1). Amine chemistry is quite versatile, reacting highly effectively with carboxylic acids, esters, and acyl halides. ${ }^{54}$ The amine-functionalized PEG- $b$-PS and PEG-b-PDLLA themselves can be made from the azidefunctionalized polymers. ${ }^{55,56}$ We envision this method being used generally for bottom-up built nanoparticles, since this 
approach is possible for any polymer without reactive side groups.

The forward synthesis of $\mathrm{H}_{2} \mathrm{~N}-\mathrm{PEG}-b$-PS 4 (Scheme 2A) commenced with the growth of polystyrene onto tert-butyl- $\alpha$ -

Scheme 2. Strategy for the Synthesis of AmineFunctionalized PEG- $b$-PS and PEG- $b$-PDLLA Polymers
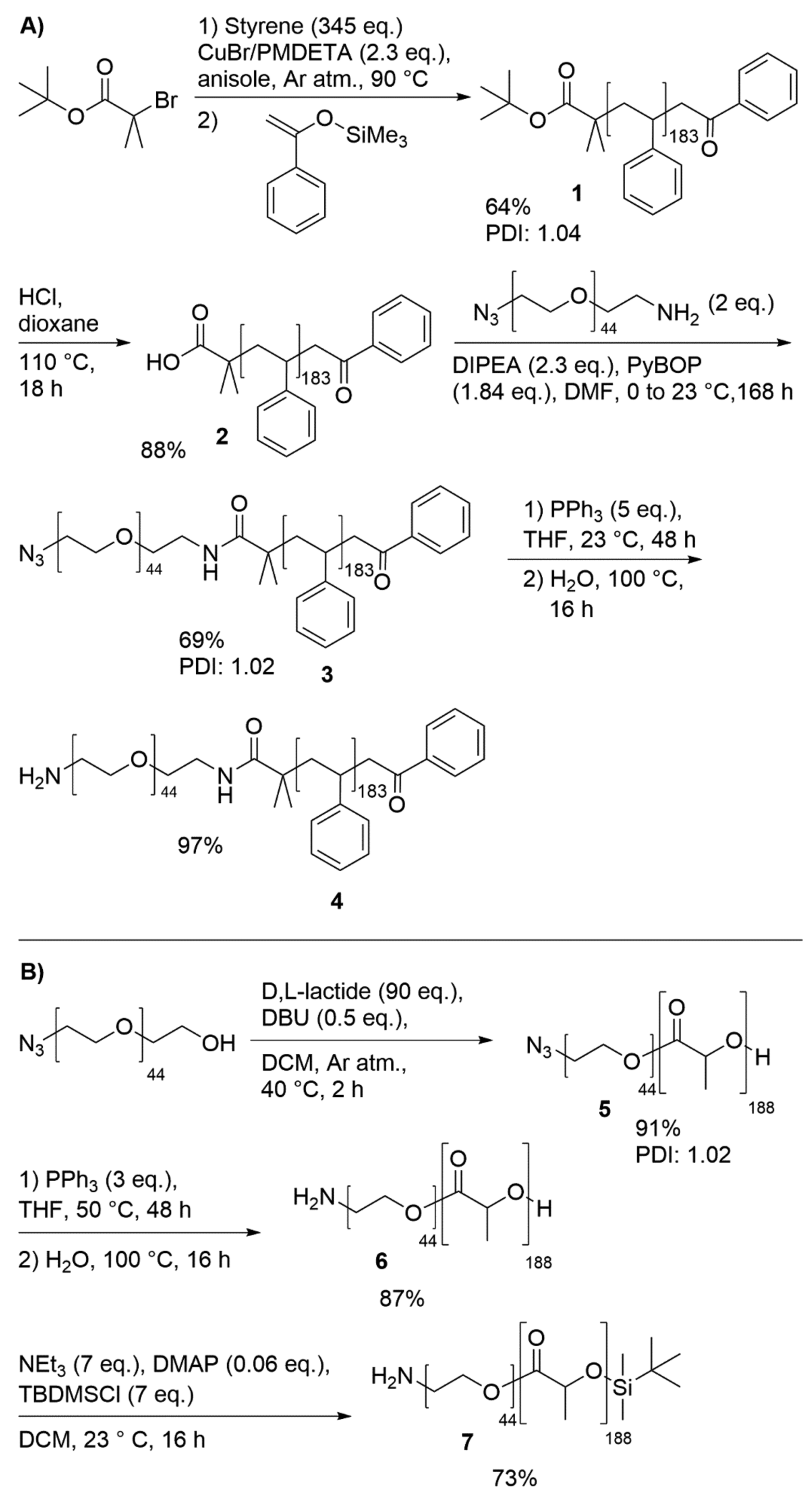

bromoisobutyrate by ATRP, to obtain $\mathbf{1}$ with an average length of 183 . This length was confirmed by ${ }^{1} \mathrm{H}$ NMR, and the GPC showed a PDI of 1.04. This was followed by deprotection to obtain 2, as described in earlier work. ${ }^{49}$ Next, we attached $\alpha$ azide- $\mathrm{PEG}_{44}-\omega$-amine via an amide bond using benzotriazole1-yloxytripyrrolidinophosphonium hexafluorophosphate (PyBOP) as the coupling reagent, together with $N, N$ diisopropylamine (DiPEA) in DMF. This was done in contrast to previous work using amine functionalization of both ends of the polymer ${ }^{40}$ in order to prevent triblock formation. Due to the large size of the polymers in comparison to the reactive groups, this reaction took $168 \mathrm{~h}$ to go to completion. Progress of the reaction was followed by TLC. Formation of 3 was corroborated by ${ }^{1} \mathrm{H}$ NMR and diffusion NMR, showing comparable diffusion speeds for both the PEG and PS signals, whereas uncoupled PEG has an approximately $10 \times$ faster diffusion speed compared to PS, indicating successful coupling (Figure S1). Finally, the azide was reduced by using a Staudinger reduction. ${ }^{57}$ An excess of triphenylphosphine was added to the polymer in THF and allowed to stir for $48 \mathrm{~h}$ to ensure formation of the iminophosphorane. Afterward, water was used to reduce the iminophosphorane to the amine, which was shown on TLC. After precipitation, this afforded 4 in $97 \%$ yield.

The forward synthesis of $\mathrm{H}_{2} \mathrm{~N}$-PEG- $b$-PDLLA 7 (Scheme 2B) started with Ring Opening Polymerization (ROP) using DBU as initiator, as described in earlier work. ${ }^{19}$ Polylactic acid was grown onto $\alpha$-azide- $\mathrm{PEG}_{44}-\omega$-amine to yield 5 with a PDI of 1.02. The terminal azide was then reduced in a similar fashion to 3 by performing a Staudinger reduction, yielding 6 in $87 \%$. Finally, in order to ensure the handles could only attach to the hydrophilic side of our block copolymer, the alcohol group at the hydrophobic end of the polymer was protected with a TBS group.

Library Synthesis. With the obtained amino-PEG- $b$-PS and amino-PEG- $b$-PDLLA block-copolymers, we started creating a library. This was done via three general methods, making it easy to couple carboxylic acids, NHS esters, and acyl halides (Scheme 3). Most of the functional handles on PEG-bPS were introduced via method A, by means of amide coupling of carboxylic acids or NHS esters using EDC coupling reagent as well as DMAP. ${ }^{58}$ Most of the functional handles on PEG- $b$ PDLLA were introduced via method $\mathrm{B}$, using PyBOP and DIPEA as coupling reagents to form an amide bond from the respective carboxylic acids and NHS esters. For this method, it was discovered that activation of the acid should be performed before adding the polymer. When adding all reagents together, NMR showed that a portion of the polymer had decomposed as a result of the reaction conditions used. The PyBOP and DIPEA appear to have reacted with the polymer instead of activating the acid. This may have caused the ester bonds of

Scheme 3. Strategy for the Functional Handle Library Synthesis of PEG-b-PS and PEG- $b$-PDLLA Polymers<smiles>CC(N)CCOCC(C)OC(C)C(=O)OCC(C)O[Si](C)(C)C(C)C</smiles>

7

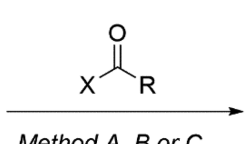

Method A, B or C

PEG-PS $57-97 \%$ PEG-PLA $28-99 \%$

$\mathrm{X}=\mathrm{OH}, \mathrm{NHS}, \mathrm{Cl}$ $\mathrm{R}=$ Functional group<smiles>[R]C(=O)NC(C)COC(C)(C)CNC(=O)C(C)(C)CC(C)C(C)C(=O)c1ccccc1</smiles><smiles>[R]C(=O)NC(C)COC(C)C(=O)OC(C)O[Si](C)(C)C(C)(C)C</smiles>

7a-m 
Table 1. Scope of the Handle Functionalization Reaction

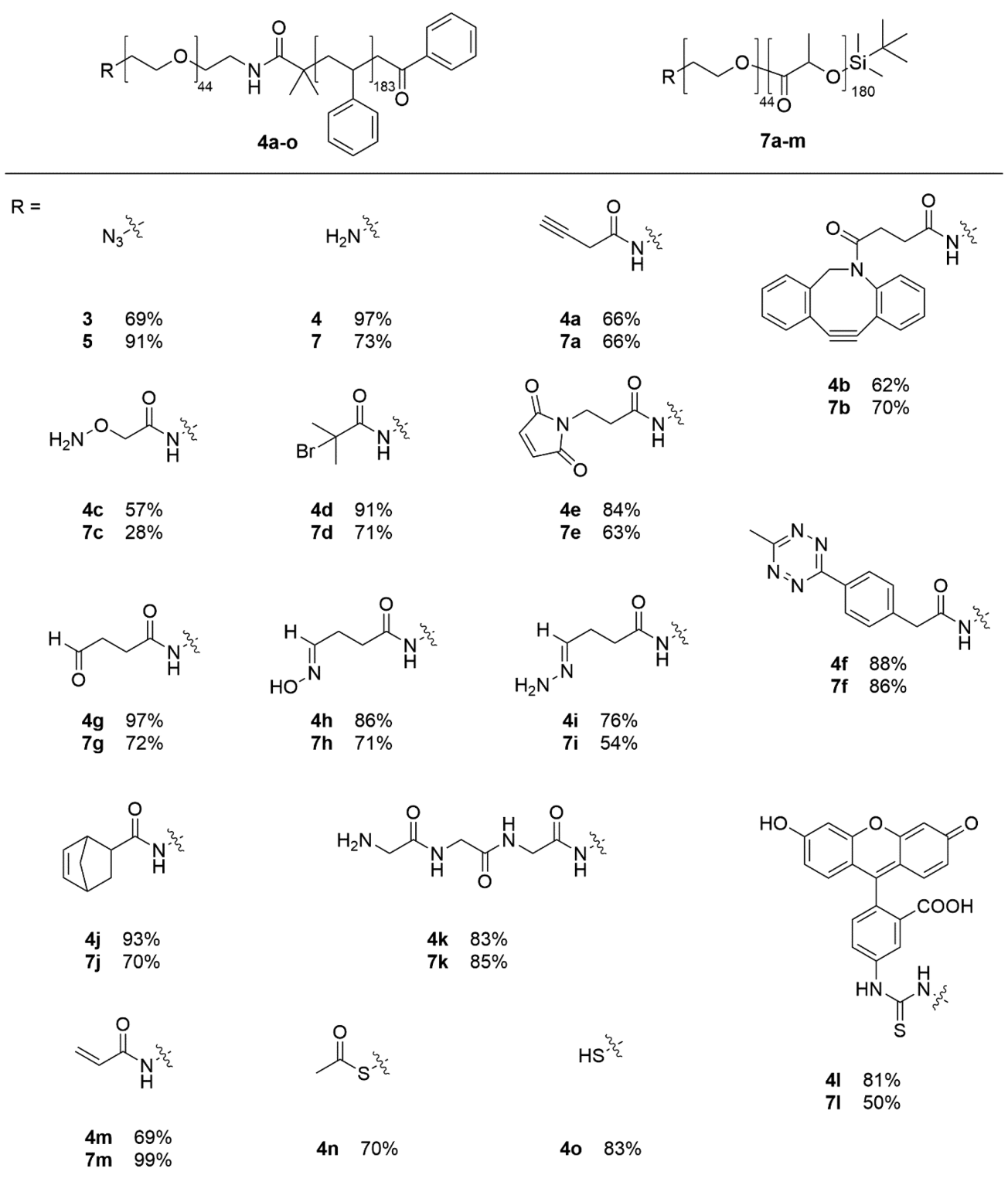

the PDLLA polymer to decompose. For this reason, the polymer is added $1 \mathrm{~h}$ after activation of the carboxylic acid. Finally, acyl halides were coupled via method C, using only $\mathrm{Et}_{3} \mathrm{~N}$ as a base. Due to the high reactivity of acyl halides, ${ }^{43}$ no further coupling reagents are required.

Proving the attachment of the varying functional groups is difficult via the conventional methods used in organic chemistry. Due to the extremely small weight percent of the functional group compared to the bulk polymer, functional groups are virtually invisible on methods such as NMR and IR spectroscopy, not being able to overcome the noise of the spectra. For this reason as well, an amine functionality was chosen as the base module, as this provides another method of proving the successful functionalization. The amide couplings were all followed by means of a Kaiser test. This qualitative test shows the presence of free terminal amine in products by appearing either blue when free amine is present or yellow when there is not. The test is able to show $99.9 \%$ completion of the amide bond formation, ${ }^{47}$ making it a very potent tool for ensuring full conversion of the polymer to the desired handle.
Using this method, virtually any functional group could be attached to the polymer, provided it does not react with the amine functionality. We aimed to make a library that shows the versatility of this approach, both from a synthetic side as well as a more biochemical side (Table 1 ). The azide ( 3 and 5 ) and amine (4 and 7) functional groups that were made during the synthesis of the modular polymers can already be used as handles, as has been demonstrated before. ${ }^{13,19,59}$ First, we made the propargyl (4a and 7a) and DBCO-functionalized polymers $(\mathbf{4 b}$ and $\mathbf{7 b})$ in decent yields. These were chosen as examples for the click reaction, which is often used in biorthogonal chemistry. Commonly, the azide handle is placed on the nanoparticle, ${ }^{18}$ but the reverse has also been shown to be successful in the biochemical field. ${ }^{60} \mathrm{Next}$, an aminooxy group ( $4 c$ and $7 c$ ) was attached in moderate yields. Although full conversion was confirmed via the Kaiser test, the lower yield is most likely due to the precipitation not being optimal with this highly polar group. The aminooxy group allows the formation of extremely stable oxime linkages with aldehyde groups, making it easy to use for both chemical and biological purposes. ${ }^{61}$ The addition of a halide linker led to the formation 
of the bromine-functionalized $\mathbf{4 d}$ and $\mathbf{7 d}$ in high yield. Having a bromine handle on the polymer allows for further polymerization after self-assembly via ATRP, as has been demonstrated. ${ }^{49}$ Next, a maleimide group (4e and 7e) was attached in good yield. These are commonly used in biorthogonal chemistry to perform Diels-Alder reactions ${ }^{62}$ and couple to thiols. ${ }^{63}$ Continuing with the biorthogonal linkage, a tetrazine group was attached as well with high yield (4f and 7f). These versatile handles can perform inversedemand Diels-Alder reactions with various functional groups, such as norbornenes and vinyl boronic acids. ${ }^{64}$ An aldehyde functionality was made in two steps ( $4 \mathrm{~g}$ and $7 \mathrm{~g}$ ) with high yield. The aldehyde had a 1,3-dioxalane protecting group to ensure no imine was formed, which was removed after the amide coupling went to completion. The aldehyde functionality can be used to make oxime bonds, similar to the aminooxy functionality, as well as form imines. From the aldehyde, two other functional handles were made; an oxime $(4 \mathbf{h}$ and $7 \mathbf{h})$ and a hydrazone $(4 \mathbf{i}$ and $7 \mathbf{i})$. Oximes can undergo a Tiemann rearrangement, providing substituted ureas. ${ }^{65}$ Hydrazones on the other hand are known for their ability to exchange functional groups with other hydrazones, making this an interesting linkage for exchanging functionalization on the nanoparticle. ${ }^{66}$ A norbornene handle $(\mathbf{4 j}$ and $7 \mathbf{j})$ was made as it can react with tetrazines, ${ }^{21}$ as well as form nitrile oxide cycloadditions. $^{24}$

In order to show the versatility of this modular approach, various examples other than biorthogonal linkage handles were made. First, a triglycine was attached to the polymer (4k and $7 \mathbf{k}$ ) in two steps, coupling and deprotection. Functionalization of nanomotors with peptides could make them recognizable by various receptors and enzymes. In this example, triglycine is recognized by the enzyme Sortase A, which allows for a biological approach for the functionalization of polymersomes. ${ }^{67}$ Next, a commonly used dye, Fluorescein isothiocyanate (FITC), was attached to the polymers (4l and 71). This dye was chosen because it is one of the most popular fluorescent probes in the scientific field. FITC has been used mainly for fluorescence detection by labeling antibodies. This allows for detection of antigens, among others. ${ }^{68}$ Due to its fluorescence, the presence of the FITC group was also determined by UV-vis (Figures S2 and S3).

Finally, an acryloyl handle was attached to the modular polymers $(4 \mathrm{~m}$ and $7 \mathrm{~m}$ ). These handles can be used to form bonds with sulfur groups, ${ }^{69}$ opening the possibility for peptideconjugated vesicles using thiol chemistry. It is of course also possible to use sulfur handles on the nanovessicle, making it able to bind substrates that feature an acryloyl group. To our knowledge, however, there have been few reports of thioldecorated vesicles being utilized in this context. ${ }^{70}$ This drove us to also pursue a thiol handle as part of our library. Since no thiol suitable for our general coupling methods could be found commercially, we opted to synthesize the thiol-functionalized polymer from scratch (Scheme 4). An acetylated thiolfunctionalized PEG was coupled to an ATRP initiator, forming 8 in moderate yield. The thiol is protected to ensure no thioesters could be formed. Afterward, polystyrene was grown onto the PEG similar to the formation of $\mathbf{1}$, leading to an acetylated thiol-functionalized PEG- $b$-PS polymer $4 \mathbf{n}$. The protected thiol is also a useful handle when incorporating multiple functional groups onto a nanoparticle; it allows for selective reactivity on the other handle, after which the thiol can be deprotected to allow further reactivity. For this reason,
Scheme 4. Strategy for the Synthesis of ThiolFunctionalized PEG- $b$-PS Polymer
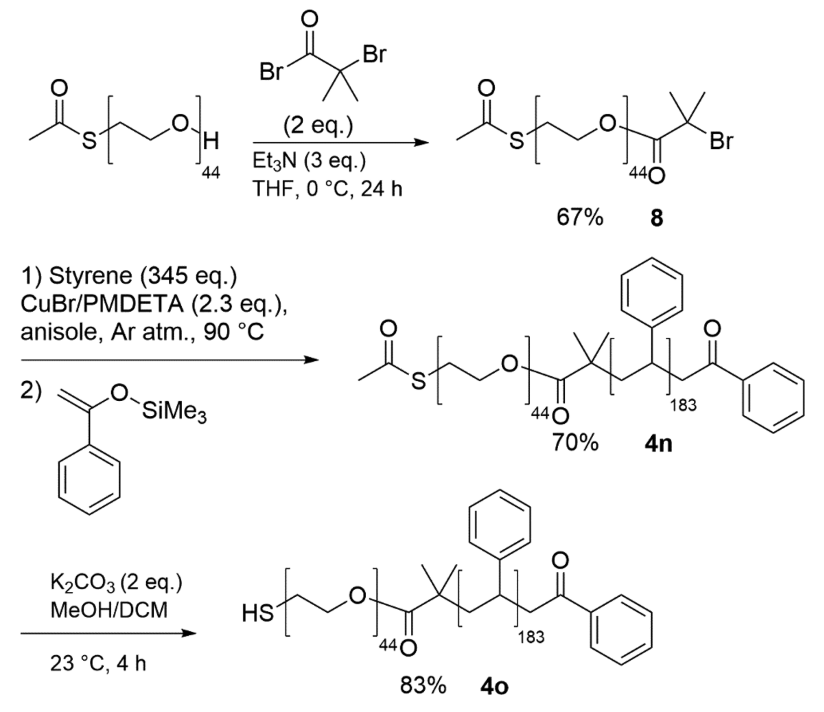

it is also incorporated in the library. Removal of the acetyl was performed by the use of a base in methanol, with addition of DCM to ensure solubility of the polymer. Upon removal of the acetyl moiety, 4o was obtained in high yield.

Formation of Polymersomes. All polymersomes were made using 90\% $\mathrm{MeO}-\mathrm{PEG}_{44}-b-\mathrm{PS}_{170}$ and $\mathrm{MeO} \mathrm{PEG}_{22}-b$ PDLLA $_{94}$, respectively, as the main component, since these materials are known to readily self-assemble into polymersomes, $^{71}$ adding $10 \%$ of the functionalized polymer. The decorated polymers are slightly longer or just as long as the unreactive polymers to ensure availability on the surface. After dissolving the polymer in organic solvent (4:1 THF/1,4dioxane), $0.5 \mathrm{~mL}$ of ultrapure water was added slowly at $1 \mathrm{~mL} /$ $\mathrm{h}$, inducing self-assembly into spherical polymersomes. Afterward, the PEG- $b$-PS polymersomes were quenched by adding $10 \mathrm{~mL}$ of ultrapure water, after which the suspension was transferred to a centrifuge tube. The suspension was purified $3 \times$ by centrifugation to remove organic solvent, and finally suspended in $1 \mathrm{~mL}$ of ultrapure water as a $10 \mathrm{mg} / \mathrm{mL}$ suspension. Polymersomes were made for all handles in the library. The integrity of the polymersomes was verified by transmission electron microscopy (TEM). All handles from the library were able to self-assemble into polymersomes without disturbance in the membrane morphology via the general method, despite size or polarity of the various handles (Figures S4-S20), comparable to polymersome formation without any functional polymers (Figure S21). DLS data also shows that all batches have similar size distributions (Figures S22-S39), averaging at $638 \mathrm{~nm}$. The DBCO handle, the sterically largest and most hydrophobic of the functional handles, can be seen in Figure 2A. This sample was also visualized by cryo-TEM to show the undisturbed polymersome structure (Figures $2 \mathrm{~B}$ and S40), as were the FITC and thiol handles (Figures S41-S43), due to their large potential impact on the structure. To ensure that the functionalized polymers are incorporated into the structure during the self-assembly, a $50 \times$ diluted FITC handle incorporated polymersome sample was examined by fluorescence spectrometry, showing an $\sim 440 \times$ increase in fluorescence compared to the blank (Figure S44). This high increase shows incorporation of the functionalized polymers in the structure. However, it is possible that large hydrophobic 

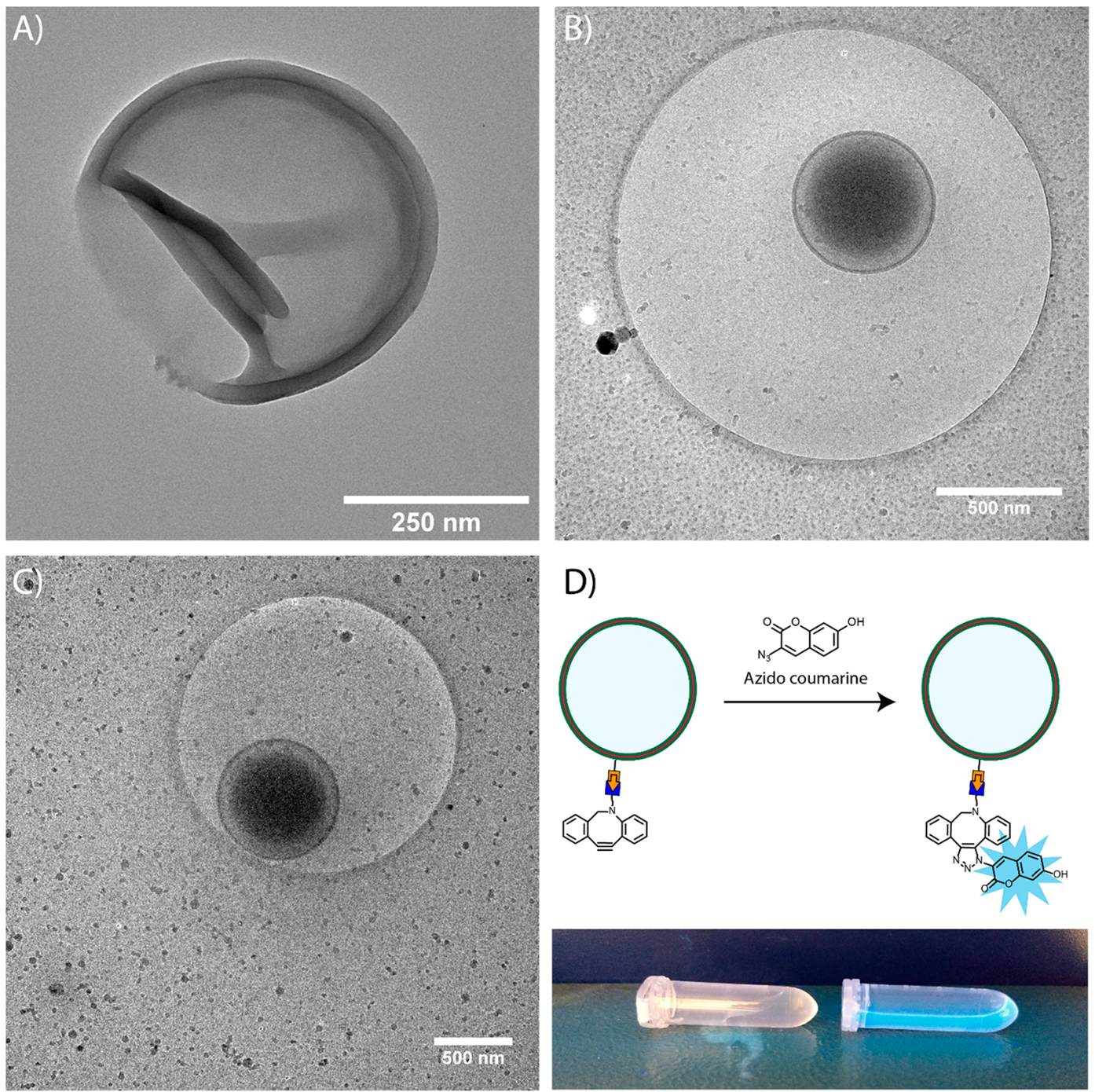

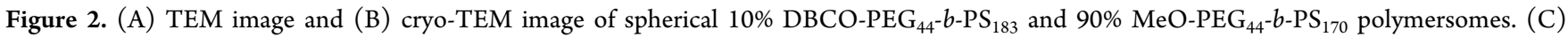

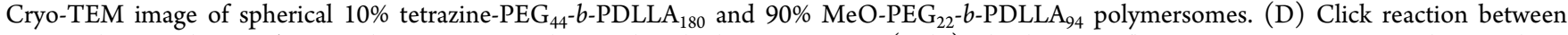
DBCO-decorated PEG- $b$-PS polymersomes and 3-azido-7-hydroxycoumarin (right), leading to fluorescence. As a control, 3-azido-7hydroxycoumarin was added to nonfunctionalized polymersomes, yielding no fluorescence (left).

probes fold into the polystyrene, making them unreachable for any reactivity to take place. This is mainly the case for the sterically larger and more hydrophobic handles. To verify the availability of the handles on the surface, we opted to test the reactivity of the largest and most hydrophobic entry in the library. For this reason, the DBCO linker was examined by reacting a $50 \times$ dilution of polymersomes with 3-azido-7hydroxycoumarin in water overnight. The cycloaddition reaction was shown to have succeeded by confirming its fluorescence visually (Figure 2D), as well as via fluorescence spectroscopy, showing an $\sim 200 \times$ increase in fluorescence compared to the blank (Figure S44). Based on this evidence, we believe this indicates the accessibility of the wide range of functional handles presented in this library.

For PEG- $b$-PDLLA, the polymers were dissolved in $1 \mathrm{~mL}$ of organic solvent (4:1 THF/1,4-dioxane), after which an equivalent of ultrapure water was added slowly at $1 \mathrm{~mL} / \mathrm{h}$. All samples formed a cloudy solution, indicating the polymersome formation. Subsequently, the samples were dialyzed for $24 \mathrm{~h}$ against ultrapure water, with a solution change after $1 \mathrm{~h}$ to remove the organic solvent. The method of dialysis was chosen instead of quenching using ultrapure water, as was done for the PEG- $b$-PS polymersomes, because quenching the structures in a swift manner led to the formation of aggregates in some cases. From several samples, cryo-TEM images were taken to verify the morphology (Figures S45-S48). The tetrazine handle is highlighted in Figure $2 \mathrm{C}$, as it is one of the more sterically larger and hydrophobic handles. The samples were analyzed by DLS to see their size distributions (Figures S49S64) averaging at $354 \mathrm{~nm}$. From these data it can be seen that the size and PDI of the polymersomes are influenced by the incorporation of different handles.

Polymersomes have been used for in vivo applications; however, sizes of $\sim 100 \mathrm{~nm}$ are optimal for biorelated applications. ${ }^{72}$ The most common method for the fabrication of small-sized polymersomes is resizing through either extrusion or sonication. ${ }^{73}$ Earlier work in our group has shown the possibility of producing small-sized polymersomes using the extrusion method. ${ }^{74,75}$ These methods make it possible to reduce the size of the average size of the sample, making the polymersomes applicable for use in biomedical applications. Another challenge is the limitation in catalysts 
currently available to drive motion. We aim to broaden the fuel scope of block copolymer based nanomotors by using homogeneous catalysis, which has been absent from the nanomotor field, having only several examples in the literature. $^{76}$ This approach, however, requires options for chemical ligation to these polymer systems. We hope this general methodology to incorporate handles allows for an expansion in the variety of fuel sources and applications of nanomotors, allowing not only for the incorporation of catalysts and enzymes, but also drugs and imaging tools.

\section{CONCLUSIONS}

In conclusion, we have developed a general route for the synthesis of terminally functionalized PEG- $b$-PS and PEG- $b$ PDLLA via a modular approach. By placing a terminal amine on the polymers, a wide scope of functionalities can be achieved without the need for repeating the polymer synthesis for every different moiety. A library containing 32 different polymers has been synthesized. The examples used in the library reflect the wide scope of nanovesicle applications, introducing new chemical ligation techniques, as well as biochemical coupling options and fluorescence incorporation. Well-defined polymersome structures with $10 \%$ incorporation of the functional polymers were generated of every polymer in the library, of both the PEG- $b$-PS and the biodegradable PEG$b$-PDLLA block copolymers. Self-assembly by using the fluorescent FITC-functionalized polymer showed the incorporation of these handles into the polymersome structure. Attachment of the fluorescent azidocoumarin to the DBCOdecorated polymersomes showed the availability of the functional groups, allowing for chemical ligation on the surface via click-reaction. Finally, we envision this methodology to be used for various polymer-based bottom-up systems, being applicable to a wide assortment of polymers, and leading to more covalent approaches in nanomotor and drug delivery design.

\section{ASSOCIATED CONTENT}

\section{SI Supporting Information}

The Supporting Information is available free of charge at https://pubs.acs.org/doi/10.1021/acs.biomac.9b01734.

TEM and cryo-TEM images of polymersomes, DLS data of polymersomes, fluorescence data, and NMR of all synthesized compounds (PDF)

\section{AUTHOR INFORMATION}

\section{Corresponding Author}

Daniela A. Wilson - Institute for Molecules and Materials, Radboud University 6525 AJ Nijmegen, The Netherlands; ○ orcid.org/0000-0002-8796-2274; Phone: +31 (0)24 36 52185; Email: d.wilson@science.ru.nl

\section{Authors}

Sjoerd J. Rijpkema - Institute for Molecules and Materials, Radboud University 6525 AJ Nijmegen, The Netherlands

Sabine G. H. A. Langens - Institute for Molecules and Materials, Radboud University 6525 AJ Nijmegen, The Netherlands

Marnix R. van der Kolk - Institute for Molecules and Materials, Radboud University 6525 AJ Nijmegen, The Netherlands

Katerina Gavriel - Institute for Molecules and Materials, Radboud University 6525 AJ Nijmegen, The Netherlands
B. Jelle Toebes - Institute for Molecules and Materials, Radboud University 6525 AJ Nijmegen, The Netherlands

Complete contact information is available at:

https://pubs.acs.org/10.1021/acs.biomac.9b01734

\section{Notes}

The authors declare no competing financial interest.

\section{ACKNOWLEDGMENTS}

The authors acknowledge the NWO Chemische Wetenschappen VIDI Grant 723.015.001 and the Ministry of Education, Culture and Science (Gravitation Program 024.001.035) for financial support. S.J.R. acknowledges Jeroen van de Wiel and Roel Maas for assistance with the fluorescence experiments.

\section{REFERENCES}

(1) Lee, J. S.; Feijen, J. Polymersomes for drug delivery: design, formation and characterization. J. Controlled Release 2012, 161 (2), $473-483$.

(2) Meng, F.; Zhong, Z.; Feijen, J. Stimuli-responsive polymersomes for programmed drug delivery. Biomacromolecules 2009, 10 (2), 197209.

(3) Esteban-Fernández de Ávila, B.; Martín, A.; Soto, F.; LopezRamirez, M. A.; Campuzano, S.; Vásquez-Machado, G. M.; Gao, W.; Zhang, L.; Wang, J. Single cell real-time miRNAs sensing based on nanomotors. ACS Nano 2015, 9 (7), 6756-6764.

(4) van Dongen, S. F. M.; de Hoog, H.-P. M.; Peters, R. J. R. W.; Nallani, M.; Nolte, R. J. M.; van Hest, J. C. M. Biohybrid Polymer Capsules. Chem. Rev. 2009, 109 (11), 6212-6274.

(5) Rijpkema, S. J.; Toebes, B. J.; Maas, M. N.; de Kler, N. R. M.; Wilson, D. A. Designing Molecular Building Blocks for Functional Polymersomes. Isr. J. Chem. 2019, 59 (10), 928-944.

(6) Discher, B. M.; Won, Y.-Y.; Ege, D. S.; Lee, J. C.; Bates, F. S.; Discher, D. E.; Hammer, D. A. Polymersomes: tough vesicles made from diblock copolymers. Science 1999, 284 (5417), 1143-1146.

(7) Zhou, W.; Feijen, J. Biodegradable polymersomes for controlled drug release. J. Controlled Release 2008, 132 (3), e35-e36.

(8) G. Tuguntaev, R.; Ikechukwu Okeke, C.; Xu, J.; Li, C.; C. Wang, P.; Liang, X.-J. Nanoscale Polymersomes as Anti-Cancer Drug Carriers Applied for Pharmaceutical Delivery. Curr. Pharm. Des. 2016, 22 (19), 2857-2865.

(9) Ahmed, F.; Discher, D. E. Self-porating polymersomes of PEGPLA and PEG-PCL: hydrolysis-triggered controlled release vesicles. J. Controlled Release 2004, 96 (1), 37-53.

(10) Onaca, O.; Enea, R.; Hughes, D. W.; Meier, W. StimuliResponsive Polymersomes as Nanocarriers for Drug and Gene Delivery. Macromol. Biosci. 2009, 9 (2), 129-139.

(11) Vriezema, D. M.; Comellas Aragonès, M.; Elemans, J. A. A. W.; Cornelissen, J. J. L. M.; Rowan, A. E.; Nolte, R. J. M. Self-Assembled Nanoreactors. Chem. Rev. 2005, 105 (4), 1445-1490.

(12) Renggli, K.; Baumann, P.; Langowska, K.; Onaca, O.; Bruns, N.; Meier, W. Selective and Responsive Nanoreactors. Adv. Funct. Mater. 2011, 21 (7), 1241-1259.

(13) Ortiz-Rivera, I.; Mathesh, M.; Wilson, D. A Supramolecular Approach to Nanoscale Motion: Polymersome-Based Self-Propelled Nanomotors. Acc. Chem. Res. 2018, 51, 1891-1900.

(14) Cabane, E.; Malinova, V.; Menon, S.; Palivan, C. G.; Meier, W. Photoresponsive polymersomes as smart, triggerable nanocarriers. Soft Matter 2011, 7 (19), 9167-9176.

(15) Salata, O. V. Applications of nanoparticles in biology and medicine. J. Nanobiotechnol. 2004, 2 (1), 3.

(16) Devaraj, N. K.; Weissleder, R. Biomedical Applications of Tetrazine Cycloadditions. Acc. Chem. Res. 2011, 44 (9), 816-827.

(17) Debets, M. F.; van der Doelen, C. W. J.; Rutjes, F. P. J. T.; van Delft, F. L. Azide: A Unique Dipole for Metal-Free Bioorthogonal Ligations. ChemBioChem 2010, 11 (9), 1168-1184. 
(18) von Maltzahn, G.; Ren, Y.; Park, J.-H.; Min, D.-H.; Kotamraju, V. R.; Jayakumar, J.; Fogal, V.; Sailor, M. J.; Ruoslahti, E.; Bhatia, S. N. In Vivo Tumor Cell Targeting with "Click" Nanoparticles. Bioconjugate Chem. 2008, 19 (8), 1570-1578.

(19) Toebes, B. J.; Abdelmohsen, L. K.; Wilson, D. A. Enzymedriven biodegradable nanomotor based on tubular-shaped polymeric vesicles. Polym. Chem. 2018, 9 (23), 3190-3194.

(20) Blackman, M. L.; Royzen, M.; Fox, J. M. Tetrazine ligation: fast bioconjugation based on inverse-electron-demand Diels-Alder reactivity. J. Am. Chem. Soc. 2008, 130 (41), 13518-13519.

(21) Barker, I. A.; Hall, D. J.; Hansell, C. F.; Du Prez, F. E.; O’Reilly, R. K.; Dove, A. P. Tetrazine-Norbornene Click Reactions to Functionalize Degradable Polymers Derived from Lactide. Macromol. Rapid Commun. 2011, 32 (17), 1362-1366.

(22) Malinge, J.; Allain, C.; Galmiche, L.; Miomandre, F.; Audebert, P. Preparation, Photophysical, Electrochemical, and Sensing Properties of Luminescent Tetrazine-Doped Silica Nanoparticles. Chem. Mater. 2011, 23 (20), 4599-4605.

(23) Zhang, Y.; Yu, M.; Zhang, C.; Ma, W.; Zhang, Y.; Wang, C.; Lu, $\mathrm{H}$. Highly Selective and Ultra Fast Solid-Phase Extraction of NGlycoproteome by Oxime Click Chemistry Using AminooxyFunctionalized Magnetic Nanoparticles. Anal. Chem. 2014, 86 (15), $7920-7924$.

(24) Truong, V. X.; Zhou, K.; Simon, G. P.; Forsythe, J. S. Nitrile Oxide-Norbornene Cycloaddition as a Bioorthogonal Crosslinking Reaction for the Preparation of Hydrogels. Macromol. Rapid Commun. 2015, 36, 1729-1734.

(25) Shao, J.; Tam, J. P. Unprotected Peptides as Building Blocks for the Synthesis of Peptide Dendrimers with Oxime, Hydrazone, and Thiazolidine Linkages. J. Am. Chem. Soc. 1995, 117 (14), 3893-3899.

(26) Hoyle, C. E.; Bowman, C. N. Thiol-Ene Click Chemistry. Angew. Chem., Int. Ed. 2010, 49 (9), 1540-1573.

(27) Ruizendaal, L.; Pujari, S. P.; Gevaerts, V.; Paulusse, J. M. J.; Zuilhof, H. Biofunctional Silicon Nanoparticles by Means of ThiolEne Click Chemistry. Chem. - Asian J. 2011, 6 (10), 2776-2786.

(28) Penelas, M. J.; Soler-Illia, G. J. A. A.; Levi, V.; Bordoni, A. V.; Wolosiuk, A. Click-based thiol-ene photografting of $\mathrm{COOH}$ groups to $\mathrm{SiO} 2$ nanoparticles: Strategies comparison. Colloids Surf., A 2019, $562,61-70$.

(29) Shi, M.; Wosnick, J. H.; Ho, K.; Keating, A.; Shoichet, M. S. Immuno-Polymeric Nanoparticles by Diels-Alder Chemistry. Angew. Chem., Int. Ed. 2007, 46 (32), 6126-6131.

(30) Jarre, G.; Liang, Y.; Betz, P.; Lang, D.; Krueger, A. Playing the surface game-Diels-Alder reactions on diamond nanoparticles. Chem. Commun. 2011, 47 (1), 544-546.

(31) Castillo, R. R.; Hernández-Escobar, D.; Gómez-Graña, S.; Vallet-Regí, M. Reversible Nanogate System for Mesoporous Silica Nanoparticles Based on Diels-Alder Adducts. Chem. - Eur. J. 2018, 24 (27), 6992-7001.

(32) Park, M.-H.; Subramani, C.; Rana, S.; Rotello, V. M. Chemoselective Nanoporous Membranes via Chemically Directed Assembly of Nanoparticles and Dendrimers. Adv. Mater. 2012, 24 (43), 5862-5866.

(33) Egli, S.; Nussbaumer, M. G.; Balasubramanian, V.; Chami, M.; Bruns, N.; Palivan, C.; Meier, W. Biocompatible Functionalization of Polymersome Surfaces: A New Approach to Surface Immobilization and Cell Targeting Using Polymersomes. J. Am. Chem. Soc. 2011, 133 (12), 4476-4483.

(34) van Dongen, S. F. M.; Nallani, M.; Schoffelen, S.; Cornelissen, J. J. L. M.; Nolte, R. J. M.; van Hest, J. C. M. A Block Copolymer for Functionalisation of Polymersome Surfaces. Macromol. Rapid Commun. 2008, 29 (4), 321-325.

(35) Figueiredo, P.; Balasubramanian, V.; Shahbazi, M.-A.; Correia, A.; Wu, D.; Palivan, C. G.; Hirvonen, J. T.; Santos, H. A. Angiopep2functionalized polymersomes for targeted doxorubicin delivery to glioblastoma cells. Int. J. Pharm. 2016, 511 (2), 794-803.

(36) Petkau, K.; Kaeser, A.; Fischer, I.; Brunsveld, L.; Schenning, A. P. H. J. Pre- and Postfunctionalized Self-Assembled $\pi$-Conjugated
Fluorescent Organic Nanoparticles for Dual Targeting. J. Am. Chem. Soc. 2011, 133 (42), 17063-17071.

(37) Gu, F.; Zhang, L.; Teply, B. A.; Mann, N.; Wang, A.; RadovicMoreno, A. F.; Langer, R.; Farokhzad, O. C. Precise engineering of targeted nanoparticles by using self-assembled biointegrated block copolymers. Proc. Natl. Acad. Sci. U. S. A. 2008, 105 (7), 2586.

(38) Diou, O.; Fattal, E.; Delplace, V.; Mackiewicz, N.; Nicolas, J.; Mériaux, S.; Valette, J.; Robic, C.; Tsapis, N. RGD decoration of PEGylated polyester nanocapsules of perfluorooctyl bromide for tumor imaging: Influence of pre or post-functionalization on capsule morphology. Eur. J. Pharm. Biopharm. 2014, 87 (1), 170-177.

(39) Petkau-Milroy, K.; Brunsveld, L. Supramolecular chemical biology; bioactive synthetic self-assemblies. Org. Biomol. Chem. 2013, 11 (2), 219-232.

(40) Meeuwissen, S. A.; Debets, M. F.; van Hest, J. C. M. Copperfree click chemistry on polymersomes: pre- vs. post-self-assembly functionalisation. Polym. Chem. 2012, 3 (7), 1783-1795.

(41) Wilson, D. A.; Nolte, R. J.; Van Hest, J. C. Autonomous movement of platinum-loaded stomatocytes. Nat. Chem. 2012, 4 (4), 268.

(42) Zou, T.; Dembele, F.; Beugnet, A.; Sengmanivong, L.; Trepout, S.; Marco, S.; Marco, A. d.; Li, M.-H. Nanobody-functionalized PEGb-PCL polymersomes and their targeting study. J. Biotechnol. 2015, 214, 147-155.

(43) Valeur, E.; Bradley, M. Amide bond formation: beyond the myth of coupling reagents. Chem. Soc. Rev. 2009, 38 (2), 606-631.

(44) Montalbetti, C. A.; Falque, V. Amide bond formation and peptide coupling. Tetrahedron 2005, 61 (46), 10827-10852.

(45) Pattabiraman, V. R.; Bode, J. W. Rethinking amide bond synthesis. Nature 2011, 480 (7378), 471-479.

(46) Kaiser, E.; Colescott, R.; Bossinger, C.; Cook, P. Color test for detection of free terminal amino groups in the solid-phase synthesis of peptides. Anal. Biochem. 1970, 34 (2), 595-598.

(47) Sarin, V. K.; Kent, S. B.; Tam, J. P.; Merrifield, R. B. Quantitative monitoring of solid-phase peptide synthesis by the ninhydrin reaction. Anal. Biochem. 1981, 117 (1), 147-157.

(48) Sivakumar, K.; Xie, F.; Cash, B. M.; Long, S.; Barnhill, H. N.; Wang, Q. A Fluorogenic 1,3-Dipolar Cycloaddition Reaction of 3Azidocoumarins and Acetylenes. Org. Lett. 2004, 6 (24), 4603-4606.

(49) Tu, Y.; Peng, F.; Sui, X.; Men, Y.; White, P. B.; van Hest, J. C. M.; Wilson, D. A. Self-propelled supramolecular nanomotors with temperature-responsive speed regulation. Nat. Chem. 2017, 9 (5), $480-486$.

(50) Sherck, N. J.; Kim, H. C.; Won, Y.-Y. Elucidating a unified mechanistic scheme for the DBU-catalyzed ring-opening polymerization of lactide to poly (lactic acid). Macromolecules 2016, 49 (13), 4699-4713.

(51) Naumovich, Y. A.; Golovanov, I. S.; Sukhorukov, A. Y.; Ioffe, S. L. Addition of HO-Acids to N, N-Bis (oxy) enamines: Mechanism, Scope and Application to the Synthesis of Pharmaceuticals. Eur. J. Org. Chem. 2017, 2017 (41), 6209-6227.

(52) Yi, L.; Shi, J.; Gao, S.; Li, S.; Niu, C.; Xi, Z. Sulfonium alkylation followed by 'click' chemistry for facile surface modification of proteins and tobacco mosaic virus. Tetrahedron Lett. 2009, 50 (7), $759-762$.

(53) Men, Y.; Li, W.; Lebleu, C.; Sun, J.; Wilson, D. A. Tailoring Polymersome Shape Using the Hofmeister Effect. Biomacromolecules 2020, 21 (1), 89-94.

(54) Opsteen, J. A.; van Hest, J. C. M. Modular synthesis of block copolymers via cycloaddition of terminal azide and alkyne functionalized polymers. Chem. Commun. 2005, 0 (1), 57-59.

(55) Toebes, J.; Cao, F.; Wilson, D. Spatial control over catalyst positioning on biodegradable polymeric nanomotors. Nat. Commun. $2019,10,5308$.

(56) Ting, W.-H.; Dai, S. A.; Shih, Y.-F.; Yang, I. K.; Su, W.-C.; Jeng, R.-J. Facile synthetic route toward poly(vinyl benzyl amine) and its versatile intermediates. Polymer 2008, 49 (6), 1497-1505.

(57) Gololobov, Y. G.; Zhmurova, I. N.; Kasukhin, L. F. Sixty years of staudinger reaction. Tetrahedron 1981, 37 (3), 437-472. 
(58) Neises, B.; Steglich, W. Simple method for the esterification of carboxylic acids. Angew. Chem., Int. Ed. Engl. 1978, 17 (7), 522-524.

(59) Opsteen, J. A.; Brinkhuis, R. P.; Teeuwen, R. L. M.; Lowik, D. W. P. M.; van Hest, J. C. M. Clickable polymersomes. Chem. Commun. 2007, 0 (30), 3136-3138.

(60) Lee, S. B.; Kim, H. L.; Jeong, H.-J.; Lim, S. T.; Sohn, M.-H.; Kim, D. W. Mesoporous Silica Nanoparticle Pretargeting for PET Imaging Based on a Rapid Bioorthogonal Reaction in a Living Body. Angew. Chem., Int. Ed. 2013, 52 (40), 10549-10552.

(61) Ulrich, S.; Boturyn, D.; Marra, A.; Renaudet, O.; Dumy, P. Oxime Ligation: A Chemoselective Click-Type Reaction for Accessing Multifunctional Biomolecular Constructs. Chem. - Eur. J. 2014, 20 (1), 34-41.

(62) Nimmo, C. M.; Owen, S. C.; Shoichet, M. S. Diels-Alder Click Cross-Linked Hyaluronic Acid Hydrogels for Tissue Engineering. Biomacromolecules 2011, 12 (3), 824-830.

(63) Martínez-Jothar, L.; Doulkeridou, S.; Schiffelers, R. M.; Sastre Torano, J.; Oliveira, S.; van Nostrum, C. F.; Hennink, W. E. Insights into maleimide-thiol conjugation chemistry: Conditions for efficient surface functionalization of nanoparticles for receptor targeting. J. Controlled Release 2018, 282, 101-109.

(64) Eising, S.; Engwerda, A. H.; Riedijk, X.; Bickelhaupt, F. M.; Bonger, K. M. Highly stable and selective tetrazines for the coordination-assisted bioorthogonal ligation with vinylboronic acids. Bioconjugate Chem. 2018, 29 (9), 3054-3059.

(65) Lin, C.-C.; Hsieh, T.-H.; Liao, P.-Y.; Liao, Z.-Y.; Chang, C.-W.; Shih, Y.-C.; Yeh, W.-H.; Chien, T.-C. Practical Synthesis of NSubstituted Cyanamides via Tiemann Rearrangement of Amidoximes. Org. Lett. 2014, 16 (3), 892-895.

(66) Higgs, P. L.; Ruiz-Sanchez, A. J.; Dalmina, M.; Horrocks, B. R.; Leach, A. G.; Fulton, D. A. Enhancing the kinetics of hydrazone exchange processes: an experimental and computational study. Org. Biomol. Chem. 2019, 17 (12), 3218-3224.

(67) Leung, M. K. M.; Hagemeyer, C. E.; Johnston, A. P. R.; Gonzales, C.; Kamphuis, M. M. J.; Ardipradja, K.; Such, G. K.; Peter, K.; Caruso, F. Bio-Click Chemistry: Enzymatic Functionalization of PEGylated Capsules for Targeting Applications. Angew. Chem. 2012, 124 (29), 7244-7248.

(68) Hermanson, G. T. Fluorescent Probes. In Bioconjugate Techniques, 3rd ed.; Hermanson, G. T., Ed.; Academic Press: Boston, 2013; Chapter 10, pp 395-463.

(69) Campos, L. M.; Killops, K. L.; Sakai, R.; Paulusse, J. M. J.; Damiron, D.; Drockenmuller, E.; Messmore, B. W.; Hawker, C. J. Development of Thermal and Photochemical Strategies for ThiolEne Click Polymer Functionalization. Macromolecules 2008, 41 (19), $7063-7070$.

(70) Rosselgong, J.; Blanazs, A.; Chambon, P.; Williams, M.; Semsarilar, M.; Madsen, J.; Battaglia, G.; Armes, S. P. ThiolFunctionalized Block Copolymer Vesicles. ACS Macro Lett. 2012, 1 (8), 1041-1045.

(71) Lim Soo, P.; Eisenberg, A. Preparation of block copolymer vesicles in solution. J. Polym. Sci., Part B: Polym. Phys. 2004, 42 (6), 923-938.

(72) Photos, P. J.; Bacakova, L.; Discher, B.; Bates, F. S.; Discher, D. E. Polymer vesicles in vivo: correlations with PEG molecular weight. J. Controlled Release 2003, 90 (3), 323-334.

(73) Hickey, R. J.; Koski, J.; Meng, X.; Riggleman, R. A.; Zhang, P.; Park, S.-J. Size-Controlled Self-Assembly of Superparamagnetic Polymersomes. ACS Nano 2014, 8 (1), 495-502.

(74) Men, Y.; Peng, F.; Tu, Y.; van Hest, J. C. M.; Wilson, D. A. Methods for production of uniform small-sized polymersome with rigid membrane. Polym. Chem. 2016, 7 (24), 3977-3982.

(75) Sun, J.; Mathesh, M.; Li, W.; Wilson, D. A. Enzyme-Powered Nanomotors with Controlled Size for Biomedical Applications. ACS Nano 2019, 13 (9), 10191-10200.

(76) Pavlick, R. A.; Sengupta, S.; McFadden, T.; Zhang, H.; Sen, A. A Polymerization-Powered Motor. Angew. Chem., Int. Ed. 2011, 50 (40), 9374-9377. 